\title{
Modeling of Stage-Discharge Using Back Propagation ANN, ANFIS, and WANN-based Computing Technique
}

\section{Ravi Shukla}

G.B. Pant University of Agriculture and Technology

\section{Pravendra Kumar}

G.B. Pant University of Agriculture and Technology

\section{Dinesh Kumar Vishwakarma}

G.B. Pant University of Agriculture and Technology

\section{Rawshan Ali}

Erbil Polytechnic University

Rohitashw Kumar ( $\nabla$ rohituhf@rediffmail.com )

Sher-E-Kashmir University of Agricultural Sciences and Technology Kashmir

\section{Alban Kuriqi}

University of Lisbon

\section{Research Article}

Keywords: Artificial neural network, Stage-discharge relationship, forecasting hydrological-modeling, neural network, Gaula barrage

Posted Date: August 17th, 2021

DOl: https://doi.org/10.21203/rs.3.rs-696059/v1

License: (9) This work is licensed under a Creative Commons Attribution 4.0 International License. Read Full License

Version of Record: A version of this preprint was published at Theoretical and Applied Climatology on November 23rd, 2021. See the published version at https://doi.org/10.1007/s00704-021-03863-y. 

$4 \quad$ Ravi Shukla ${ }^{1}$, Pravendra Kumar ${ }^{1}$, Dinesh Kumar Vishwakarma ${ }^{2 *}$, Rawshan Ali $^{3}$, Rohitashw

\section{WANN-based Computing Technique \\ Modeling of Stage-Discharge Using Back Propagation ANN, ANFIS, and} Kumar $^{4 *}$ and Alban Kuriqi ${ }^{5}$

${ }^{1}$ Department of Soil and Water Conservation Engineering, G.B. Pant University of Agriculture and Technology, Pantnagar, Uttarakhand 263145, India

${ }^{2}$ Department of Irrigation and Drainage Engineering, G.B. Pant University of Agriculture and Technology, Pantnagar, Uttarakhand 263145, India;

${ }^{3}$ Department of Petroleum, Koya Technical Institute, Erbil Polytechnic University, Erbil 44001, Iraq;

${ }^{4}$ College of Agricultural Engineering and Technology, Sher-e-Kashmir University of Agriculture and Technology of Kashmir, Srinagar, Jammu, and Kashmir 190025, India; $\underline{\text { rohituhf@rediffmail.com }}$

${ }^{5}$ CERIS, Instituto Superior Técnico, University of Lisbon, 1649-004 Lisbon, Portugal;

* Corresponding author: rohituhf @ rediffmail.com (Rohitashw Kumar)

17 


\section{Modeling of Stage-Discharge Using Back Propagation ANN, ANFIS, and}

\section{WANN-based Computing Technique}

Ravi Shukla ${ }^{1}$, Pravendra Kumar ${ }^{1}$, Dinesh Kumar Vishwakarma ${ }^{2 *}$, Rawshan Ali ${ }^{3}$, Rohitashw Kumar $^{4 *}$ and Alban Kuriqi ${ }^{5}$

\section{Abstract}

The development of the stage-discharge relationship is a fundamental issue in hydrological modeling. Due to the complexity of the stage-discharge relationship, discharge prediction plays an essential role in planning and water resource management. The present study was conducted for modeling of discharge at the Gaula barrage site in Uttarakhand state of India. The study evaluated, Adaptive Neuro-Fuzzy Inference System (ANFIS), Artificial Neural Network (ANN) and Wavelet-Based Artificial Neural System (WANN) based models to estimate the discharge. The daily data of 12 years (2007-2018) were used to train and test the models. The Gamma test was used to identify the best model for discharge prediction. The input data having a stage with one-day lag and discharge with one and two-days lag and current-day discharge as output was used for discharge modeling. In the case of ANN models, the back-propagation algorithm and hyperbolic tangent sigmoid activation function was used. WANN used Haar, a trous based wavelet function. In ANFIS models, triangular, psig, generalized bell, and Gaussian membership functions were used to train and test the models. The models were evaluated qualitatively and quantitatively using correlation coefficient, root means square error, Willmott index, and coefficient of efficiency. It was found that ANFIS model performed better than ANN and WANN-based models for discharge prediction at the Gaula barrage.

Keywords: Artificial neural network, Stage-discharge relationship, forecasting hydrologicalmodeling, neural network, Gaula barrage. 


\section{Introduction}

Modeling stage-discharge correlation is critical and among the most severe challenges in hydrology, planning and management of water resources. As a result, accurate rainfall and runoff modeling are essential for increasing the storage capacity of reservoirs, flood mitigation and protection, supply of water, hydroelectric project design, and water resource management in an area with high topography variability (Davies and Hall, 1992).It can mitigate the environmental effects of climatic occurrences and improve the efficiency of the outputs. During floods measurement of direct discharge is expensive, time-consuming and perhaps impossible due to the complexity of the hydrological system. Mostly discharge records are obtained by converting recorded water levels to discharges using an expressed functional connection in a rating curve. A calibrated stage-discharge rating is a simple, inexpensive, and rapid method of estimating discharge (Kennedy, 1984; Herschy, 1999). The following power curve is commonly used to represent the stage-discharge rating(Herschy 1999):

$Q=m(n+H)^{\propto}$

Where $\mathrm{Q}=$ discharge $\left(\mathrm{L}^{3} \mathrm{~T}^{-1}\right), \mathrm{H}=$ stage $(\mathrm{L}), \propto$ is an index exponent, depending on the topic of study, while $\mathrm{m}$ and $\mathrm{n}$ are constants.

The functional relation between discharge and stage is complex and time-varying process and cannot handled by a simple grading curve (Bhattacharya and Solomatine 2000). Apart from this, data-based models establish input-output relationships without considering the physical rules and can be calibrated using a relatively small data set. In recent years artificial neural networks (ANNs), statistical models, wavelets and neuro-fuzzy coupled with WANN and multi-layer perceptron neural network (MLPNN) (Rath et al. 2013; Sehgal et al. 2014b; Akrami et al. 2014; Saha et al. 2015; Atiaa 2015; Al-Abadi 2016; Malik et al. 2017, 2018; Singh et al. 2018; Sanikhani et al. 2019; Khan et al. 2020; Dalkiliç and Hashimi 2020; Rehamnia et al. 2021).ANN is the most commonly used machine learning technique and is widely used in different areas of 
water-related research, including rainfall-runoff modeling(Akrami et al. 2014; Adnan et al. 2021a; Annayat et al. 2021), discharge prediction, and water quality prediction(Tayfur and Singh 2011; Li and Cheng 2014; Taormina and Chau 2015), estimation of parameters in groundwater (Karahan and Ayvaz 2008; Sadeghi-Tabas et al. 2016; Eryiğit 2021), water retention curve (Bayat et al. 2013; D’Emilio et al. 2018; Amanabadi et al. 2019), soil temperature at different soil depth (Wu et al. 2013).

In several hydrological process for wavelet-based hybrid models have been effectively used in water resources studies with excellent results (Sahay and Srivastava 2014; Sehgal et al. 2014a). In the last decade, wavelet-based hybrid model for a vast number of research areas, namely daily river discharge and streamflow(Güneş et al. 2021; Kambalimath S and Deka 2021; Saraiva et al. 2021; Wang et al. 2021), rainfall and runoff (Alizadeh et al. 2017; Vahid et al. 2019; Adnan et al. 2021b) forecasting of the hydrological event (Liu et al. 2011; Nourani and Andalib 2015; AlAbadi 2016; Shoaib et al. 2016), annual precipitation trends (Partal and Küçük, 2006) flood forecasting (Adamowski, 2008), soil temperature at different soil depth (Hariharan et al. 2009; Araghi et al. 2017). Many researchers have found that the WNN model, which is constructed by combining wavelet analysis with ANN usage, can make accurate predictions. Coulibaly and Burn (2004) and Özgür (2009) used it to predict the river discharge of the Aegean River and create a WNN model, the streamflow values from the previous days were used as an input parameter in the WNN model.

Jang introduced the concept of ANFIS in 1993 (Jang 1993). A versatile hydrologic modeling technique can predict rainfall-runoff forecasting and flood risk management. In ANFIS, IFTHEN rules are paired with membership functions that can output inputs and produce outputs. The group of researchers that modeled the flow of the Baitarani River in India modeled the flow with ANFIS using the hydrological time series (Nayak et al. 2004); a successful estimation emerged using ANFIS that the original flow series' statistical properties were preserved. Dastorani et al. (2010) suggested a hybrid adaptive neuro-fuzzy inference system (ANFIS) and 
wavelet can be used to predict the missing data of streamflow (gauging stations) using data from nearby places, and Ozger (2010) addressed a wavelet-neuro fuzzy model for significant wave height modeling. Shiri and Kisi (2010) suggested utilizing a wavelet and neuro-fuzzy conjunction model for short-term and long-term streamflow forecasting. The adaptive neuro-fuzzy inference system (ANFIS) was created to represent the fundamentally unpredictable nature of hydrologic systems( Abebe et al. 2000; Vafakhah and Kahneh (2016).

Now a day's machine learning has been used to simulate non-linear hydrologic systems. Particularly, ANNs (Bayat et al. 2013; Taormina and Chau 2015; Alizadeh et al. 2017; D'Emilio et al. 2018; Sihag et al. 2019a; Karimi et al. 2020; Dalkiliç and Hashimi 2020; Annayat et al. 2021; Bajirao et al. 2021), adaptive neuro-fuzzy inference system ANFIS(Nayak et al. 2004; Dastorani et al. 2010; Sehgal et al. 2014a; Vafakhah and Kahneh 2016; Amanabadi et al. 2019; Sihag et al. 2019b; Sanikhani et al. 2019; Sihag et al. 2019a; Dalkiliç and Hashimi 2020) WANN (Nourani and Andalib 2015; Alizadeh et al. 2017; Araghi et al. 2017; Bajirao et al. 2021)and support vector machine (SVM) (Jain 2012; Li and Cheng 2014; Sudheer et al. 2014; Kalteh 2015; Nourani and Andalib 2015; Sihag et al. 2017; Saraiva et al. 2021) have been recognized as effective tools for modeling complex hydrologic systems.

This paper aims to study ANNs, ANFIS, WANN models for stage-discharge forecasting evaluated the model's performance with actual field data. Actual input factor and actual length of training data are specific objectives of this study. Two different multi-artificial intelligence models for hydrological modeling were used in this work. In additional model assessment indices were used to provide a better understanding of the estimated data using models. The study results evaluated for future research of hydrological processes using different indexes (Pearson correlation coefficient (PCC), root mean squared error (RMSE), Nash-Sutcliffe efficiency (CE), and Willmott Index (WI) and coefficient of determination $\left(\mathrm{R}^{2}\right)$ ). This study aimed to determine the stage-discharge values of the Gaula barrage is located at Kathgodam near Haldwani (Nainital) Uttarakhand with objectives of gamma test using, ANN, ANFIS, and WANN approaches . 
A barrage across the Gaulariver known as Gaula barrage is located at Kathgodam near

Haldwani (Nainital). The Barrage is a landmark for the local residents and provides irrigation water for the Bhabhar area. The Gaula river originates in the lower Himalayas from a place called Sattal lake and flows southpastKathgo dam, Haldwani, Kiccha, finally joining the Ramganga river about $15 \mathrm{~km}$ north-west of Bareilly in Uttar Pradesh. It is a $578 \mathrm{~km}$ long river.

It is mainly a spring-fed river and is a source of water for Haldwani and Kathgodam. The area lies in sub-tropical to sub-humid climates and located at $29.27^{\circ} \mathrm{N}$ and $79.53^{\circ}$ E Latitude and Longitude, respectively. The average elevation of the area is $554 \mathrm{~m}$ from the sea surface. The location of the Gaula river basin area is depicting in Fig. 1. There are four seasons viz. the cold season (November to February),t the hot season ( March to May) and southwest monsoon season occurs ( Mid-June to September) following the post-monsoon season (October to November). The annual average rainfall in the area is $2095 \mathrm{~mm}$ and the maximum annual precipitation received from June to October. The highest average monthly maximum temperature of $35.5^{\circ} \mathrm{C}$ is recorded in June. In contrast, the lowest of $8.3^{\circ} \mathrm{C}$ is recorded in December.

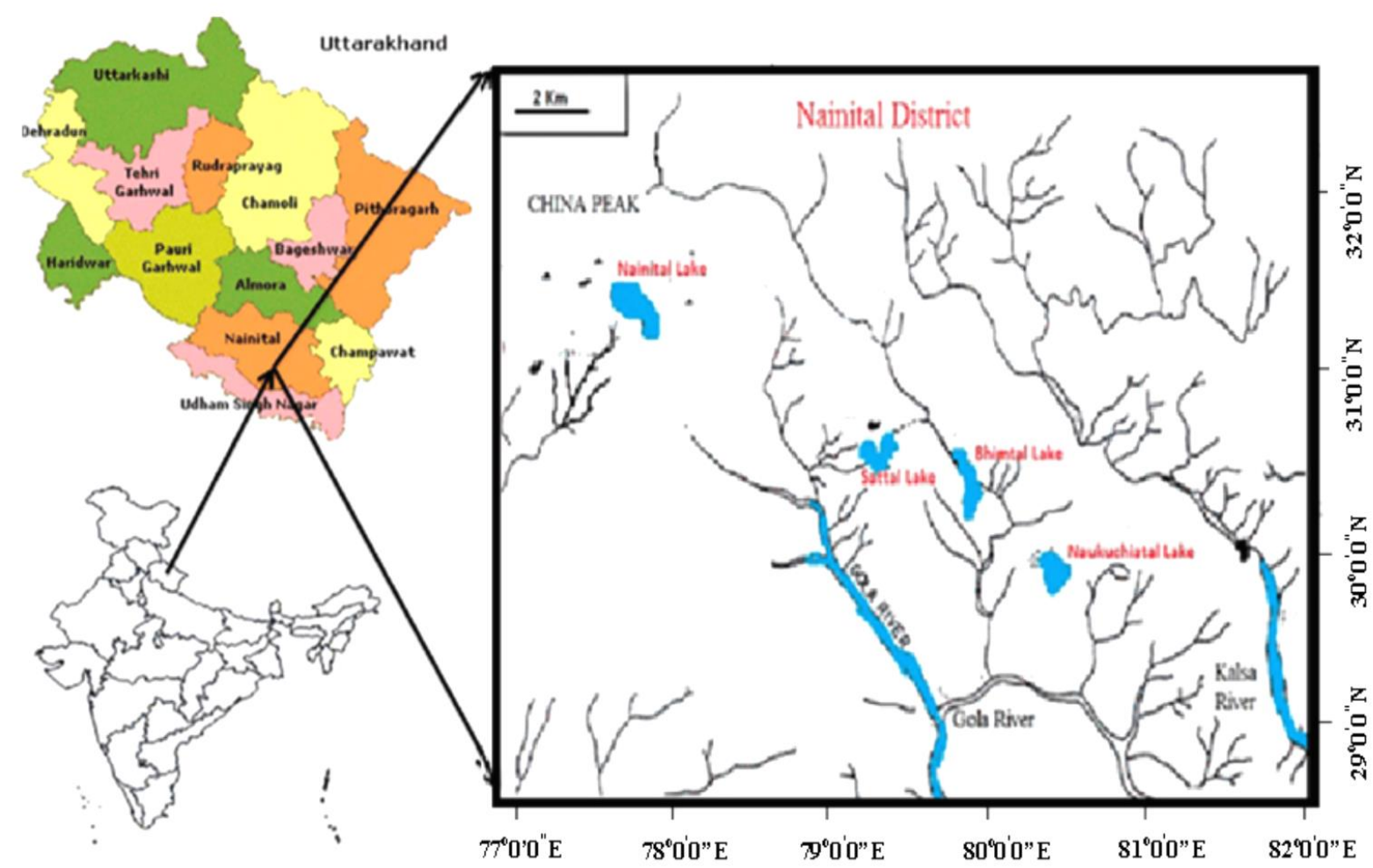


Fig. 1 Location map of Gaula barrage is located at Kathgodam near Haldwani (Nainital)

137 Owing to countless weathering resulting in folding, faulting, and thrusting, the upper level of 138 the Gaula region is composed of slates, quartzites, and graphite. The upper reach of the Gaula 139 region is separated from the Ramgarh region, which comprises slates, phyllites, quartzites, and 140 marble integrally associated with granite and quartz. The Ramgarh region is separated from the 141 Jaunsar region, which consists of basalticrocks intimately associated with quartzite and slates.

142 The valley slopes of the Gaula region are dominantly deep, well-drained, fine-loamy soils hi...ng 143 moderately acidic characteristics and having low water capacity soils. The everyday meteorological information of 12 years (2007-2018) was gathered from the Office of Irrigation Division, Kathgodam (Nainital), Uttarakhand.

\section{Methodology}

In this study ANN, ANFIS and WANN models for estimation of stage-discharge relationship were developed. These different models used for anticipating every day stage-discharge relationship. The flowchart of the proposed methodology for Stage-Discharge estimation at the Gaula Barrage is illustrated Fig.2. 
Input variables collected from Gaula barrage (2007-2018)

\begin{tabular}{|l|l|l|l|l|}
\hline $\mathrm{H}_{\mathrm{t}-2}$ & $\mathrm{H}_{\mathrm{t}-1}$ & $\mathrm{Q}_{\mathrm{t}-1}$ & $\mathrm{Q}_{\mathrm{t}-2}$ & $\mathrm{H}_{\mathrm{t}}$ \\
\hline
\end{tabular}

Applied the Gamma test to select the best input combination $\left(\mathrm{H}_{\mathrm{t}-2}, \mathrm{H}_{\mathrm{t}-1}, \mathrm{Q}_{\mathrm{t}-1} \mathrm{Q}_{\mathrm{t}-2}, \mathrm{H}_{\mathrm{t}}\right)$

Divided the whole dataset into training ang testing datasets (70:30)

Developed ANN model using training dataset $(70 \%)$

in MATLAB (R2015a) software
Developed ANFIS model using training dataset $(70 \%)$

in MATLAB (R2015a) software
Developed WANN model using training dataset $(70 \%)$ in

MATLAB (R2015a) software

Testing of all develop models such as ANN, ANFIS, WANN models using 30\% datasets

Qualitative and quantitative analysis was considered for evaluating the performance of developed models

Statistical and hydrological indices (Pearson correlation coefficient (PCC), root mean squared error (RMSE), Nash-Sutcliffe efficiency (CE), Willmott Index (WI), and coefficient of determination $\left(\mathrm{R}^{2}\right)$ were used as quantitative performance for all models to find the best developed model.

Fig. 2 Flowchart of Stage-Discharge relationship methodology of the study.

\subsection{ANN}

A neural network is a type of artificial intelligence that replicates a human brain activity. In machine learning, categorization, speech, vision, and control systems, neural networks are main computing tools for solution of complex non-linear problems. The network consists of many simple processing devices connected by weighted connections following a predetermined architecture. A neuron is made up of multiple inputs and a single output. The number of input and 
output neurons in the input and output layers is determined by the problem being simulated. The number of input variables equaling the number of input neurons and the number of output variables equaling output neurons. The ideal number (hidden layers) and hidden neurons are frequently challenging to determine because there is no standard way for doing so. By altering the connection weights, these networks learn from the training data. Artificial neural network designs are built and deployed in a variety of hydrology and hydraulics domains.

Most research using neural networks to solve water resource challenges has used backward propagation and radial basis function types (Govindaraju and Rao 2013). There are different types of ANNs used based on structures. The Multilayer Perceptron (MLP) network was used in several ANN paradigms (Lippmann 1987; Hornik et al. 1989). Layers of parallel processing nodes make up the MLP network.

Forward feed neural network arranged in layers to neurons and one or more hidden layers exist between input and output layer. Each layer's units are connected to the subsequent layer's units via a connection weight $\mathrm{w}$ that is modified during training. A data pattern is consisting of the values $x_{i}$ in the input layer $i$ is carried forward to the first hidden layer $j$. Each remote unit is fed the weighted outputs $w_{j i} x_{i}$ from the previous layer's units. These are added together to give a net value, translated via an activation function into an output value. The components of an ANN design and its processing unit are depicted in Fig.3 (a) and (b).

In Fig. 3 (a), five-layer feed-forward ANN consisting of three layers: input, hidden, and output. $x_{1}, x_{2}, x_{3}, x_{4} . . x_{d}$ are the input layer neurons; $k_{1}, k_{2}, k_{3}, k_{4} . . k_{d}$ are the hidden layer neurons; and $y_{1}, y_{2}, y_{3}, y_{4 . .} y_{d}$ are the output layer neurons.Multiple inputs and a single output make up a neuron. A summation function is obtained by adding the inputs and their weights. An activation function, which might be a step, sigmoid, threshold, linear, and so on, determines a neuron's output. 
190
Hidden layer

Target layer

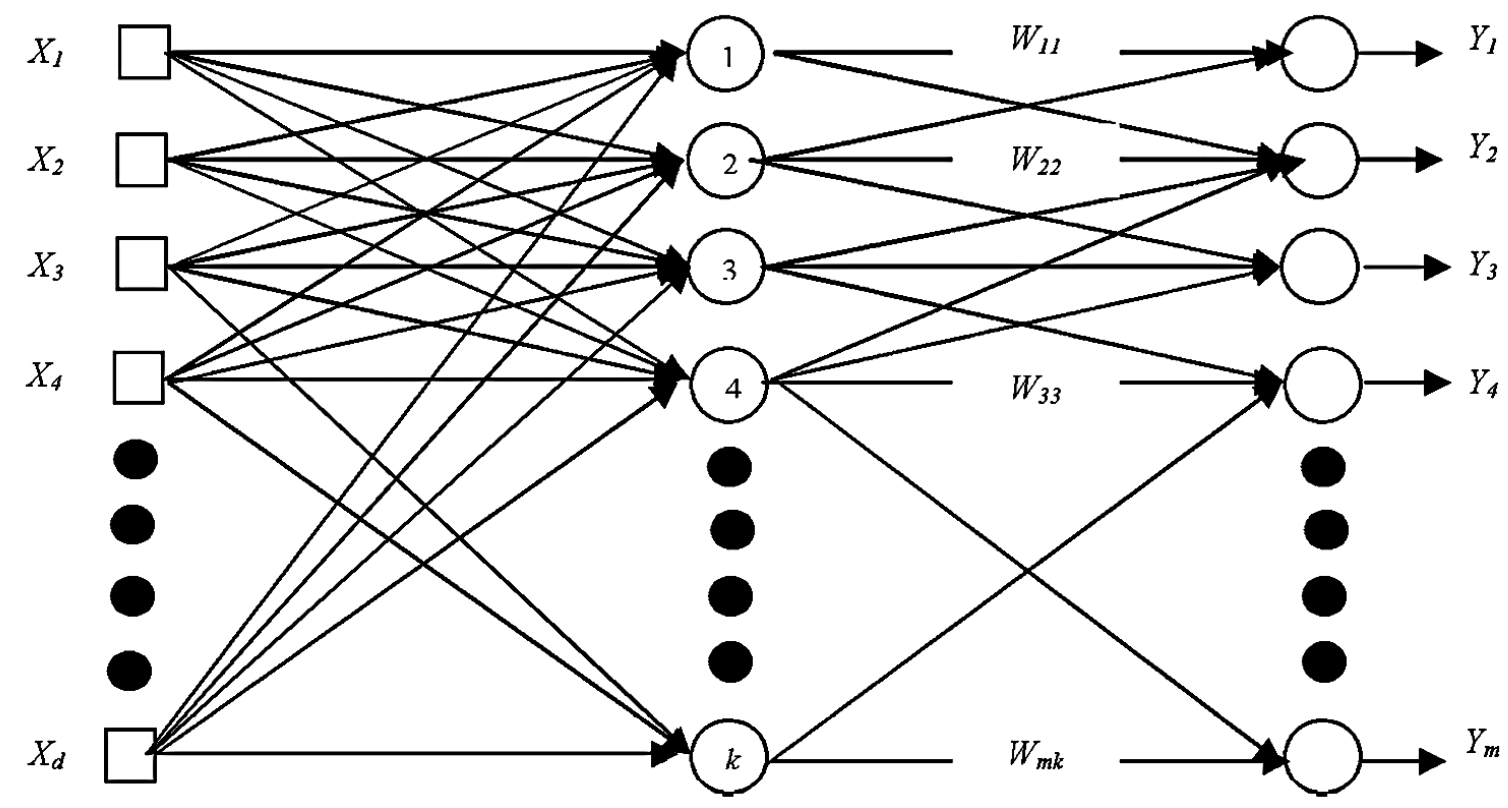

(a)
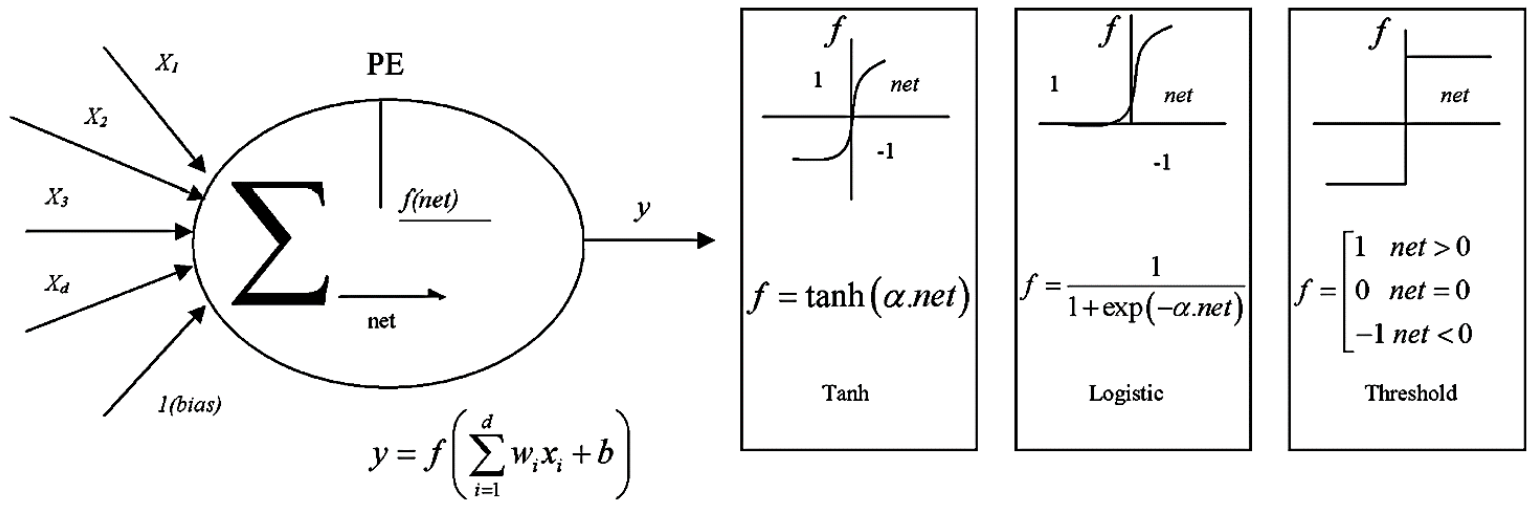

(b)

Fig.3. (a) Artificial neural network architecture with a single hidden layer; (b) A processing node with widely used non functions

The five-layer neural network depicted in Fig. 3(a-b) is composed of layers $i, j$, and $k$ with interconnection weights $w_{i j}$ and $w_{j k}$ between the layers of neurons. Each neuron in a layer receives and analyses weighted input from the preceding layer and then transmits its output via links to nodes in the subsequent layer. The weight coefficient $w_{i j}$ is used to describe the link between the $i^{\text {th }}$ and $j^{\text {th }}$ neurons, while the threshold coefficient $b$ is used to describe the $i^{\text {th }}$ neuron. The weight 
201 coefficient indicates the significance of a particular connection in the network. The $i^{\text {th }}$ neuron's

202 output value is calculated as follows(Haykin and Lippmann 1994; Haykin 2010):

$$
\begin{aligned}
& x_{i}=f\left(\epsilon_{i}\right) \\
& \epsilon_{i}=b_{i}+\sum_{j \epsilon_{i}^{-1}} w_{i j} x_{j}
\end{aligned}
$$

Where, $f\left(\epsilon_{i}\right)=$ activation function. With formally added neuron $\mathrm{j}$, where $\mathrm{x}_{\mathrm{j}}=1$, Sigmoid shape 204 activation functions are typically defined as:

$$
f\left(\epsilon_{i}\right)=\frac{1}{1+e^{-\epsilon}}
$$

205 The weight updates are calculated using the following formula

$$
\Delta w_{i j}(t)=-\eta \frac{\partial E}{\partial w_{i j}}+\mu \Delta w_{i j}(t-1)
$$

\section{Where}

$\eta=$ learning rates and $=$ momentum rates, $E=$ error or objective function, and $\Delta w_{i j}(t) \mathrm{I}=$ weight increments between nodes $i$ and $j$ for iterations $t$ a nd $\Delta w_{i j}(t-1)$ are the weight increments between nodes $i$ and $j$ for iterations $t$-1. The algorithm can be found in Fausett (2006), Haykin (2010), and (Haykin and Lippmann 1994).

\subsection{ANFIS}

Jang (1993) was the first to introduce ANFIS, which uses a neural network learning method. The development of ANFIS, introduced by Jang, combines ANN learning and fuzzy logic to produce good learning in quantity and modeling (1993).In terms of peak flow forecast accuracy and computational error, ANFIS outperforms the ANN model (Nourani and Komasi 2013). ANFIS uses linguistic knowledge from fuzzy logic and ANN learning capabilities for automated fuzzy. The ANFIS model with fuzzy inputs and neural network can solve complex problems..Fuzzy inference systems are also helpful because they merge the informative essence of membership 
functions with the strength of neural networks. Using fuzzy rules as a pre-processor to a neural network helps one integrate human intelligence to draw inferences and make decisions. The ANFIS model uses back-propagation to optimize the member function parameters (fuzzy rules). The neural network's duty is made more accessible by fuzzification, which characterizes inputs that aren't distinct, resulting in a more robust overall model.

ANFIS govern different set rules which can have the potential to learning non-linear equations. The directional links are connected through nodes. Each node has a specific function and consists of fixed parameters (Genç et al. 2014). Takagi-Sugeno type fuzzy system is an essential fuzzy system and stores IF-THEN rules (Ebtehaj and Bonakdari 2014). Takagi-Sugeno is the most accurate and frequently used in fuzzy modeling (Jang 1993). Sugeno model ( First order), with two fuzzy is as follows;

Rule 1: if $x$ is $A_{1}$ and $y$ is $B_{1}$, then $f_{1}=p_{1} x_{1}+q_{1} y+r_{1}$

$$
\text { Rule 1: if } x \text { is } A_{2} \text { and } y \text { is } B_{2} \text {, then } f_{2}=p_{2} x_{2}+q_{2} y+r_{2}
$$

$A_{i}$ and $B_{i}$ are the fuzzy sets for input $x$ and $y$, respectively, and $p_{i}, q_{i}$, and $r_{i}$ are the consequent/output function (f). These design parameters are estimated during the training process. Weights $\mathrm{w}_{1}$ and $\mathrm{w}_{2}$ are assigned to rules 1 and 2, respectively (Eq. 6-7). The weighted average is calculated as:

$$
f=\frac{w_{1} f_{1}+w_{2} f_{2}}{w_{1}+w_{2}}
$$

In a range of domains, including groundwater investigations, such as estimating hydraulic parameters, ANFIS can produce better results with fewer constraints than ANN and FIS models. There are five layers in the ANFIS structure. In the first layer, input nodes: Using the membership function, each node in this layer generates membership values dependent on each appropriate fuzzy set. 
Layer 1 Each input are fuzzified for each node output in this layer. This fuzzy set's membership

240 functions can be a triangular, trapezoidal, generalized bell, or Gaussian. In this layer, every node function of every node $i$ has a membership function that determines every node $i\left(\mathrm{Q}_{1, i}\right)$.

$$
\begin{aligned}
& O_{1, i}=\mu_{A_{i}}(x) \text { for } i=1,2 \\
& O_{1, i}=\mu_{B_{i-2}}(y) \text { for } i=3,4
\end{aligned}
$$

242 where, $x$ and $y$ are the input to the node $i(i=1,2$ for $x$ and $i=3,4$ for $y)$ and $A_{i}\left(\right.$ or $\left.B_{\mathrm{i}-2}\right)$ is the

243 fuzzy set associated with this node, and MFs characterize it $\mu_{A_{i}}$ and $\mu_{B_{i-2}}$, respectively. $A$ and $B$ 244 can be any membership functions. For the Generalized bell function, the output of the first layer 245 ( $i^{\text {th }}$ node) is determined as:

$$
O_{1, i}=\mu_{A_{i}}(x)=\frac{1}{1+\left(\frac{\left(x-c_{i}\right)}{a_{i}}\right)^{2 b_{i}}}
$$

Layer 2: The AND/OR operator is used in this layer to generate a single output that indicates the firing strength of a rule that conducts the fuzzy operation. Each node in this layer is classified as a stable node that multiplies incoming signals before sending them to the next layer.

$$
O_{2, i}=w_{i}=\mu_{A_{i}}(x) \mu_{B_{i}}(y) \text { for } i=1,2
$$

249 Layer 3: In the third layer, medium node to determine the ratio of each ignition factor $i$ to the sum of all ignition laws. Each node in this layer is a fixed node labeled N. The $i^{\text {th }}$ node calculates the ratio of the $i^{\text {th }}$ rule strength to the sum of all rule's strength.

$O_{3, i}=\overline{w_{l}}=\frac{w_{i}}{w_{1}+w_{2}}$ for $i=1,2$

252 Layer 4: This layer is called as de-fuzzification layer, in which every node is adaptive 253 (adjustable) and marked by a square. The output of this layer ( $i^{\text {th }}$ node) is obtained from the product of the normalized firing strength $\left(\overline{W_{l}}\right.$, the output of layer 3$)$ and the consequent function (f), which is expressed as: 


$$
O_{4, i}=\bar{w}_{l} f_{i}=\bar{w}_{l}\left(p_{i} x+q_{i} y+r_{i}\right) \text { for } i=1,2
$$

The $\bar{w}_{l}$ is the output of the antecedent layer, and $r_{i}, p_{i}$, and $q_{i}$, are consequent parameters of $i^{t h}$ node.

Layer 5: The fifth layer, also called output node, the single node in this layer is the system's overall output, which is the summation of all coming signals. Therefore, each fuzzy rule are transformed into non-fuzzy output.

$O_{4, i}=\sum_{i} \bar{w}_{\imath} f_{i}=\frac{\sum_{i} w_{i} f_{i}}{\sum_{i} w_{i}}$ for $i=1,2$

Thus, the input vector fed layer by layer through the network layer. The two key steps for applying ANFIS to applications are the identification process of the structure and the identification step of the parameters. The identification phase of the parameters involves the adjustment of the premise and consequence parameters.

ANFIS is a TSK fuzzy inference system utilized with the hybrid learning algorithm to model stage-discharge relationships. A fuzzy system is a method of integration where the final fuzzy system is optimized via ANN training. It maps input through the membership function and its associated parameters. Neural network training algorithms fit different parameters. Initial fuzzy rules and fuzzy structure provide some information for generating the FIS. ANFIS used a hybrid algorithm for training which is a combination of least square and gradient descent methods. In this study, the Sugeno type of FIS with a hybrid learning optimization method was used to develop stage-discharge models in MATLAB software.

\subsection{Wavelet neural networks (WNNs)WNNs}

It is seen that Fourier analysis has some severe drawbacks; while transforming data to the frequency domain, all the time information is lost. In other words, it becomes impossible to predict when a particular event occurs. Wavelet analysis is helpful to capture low-frequency 
277 information having long time intervals and high-frequency information having short time 278 intervals as per need (Rajaee et al. 2009).

Dennis Gabor (1947) analyzed a small section of signal using windowing technique of Short Time Fourier Transform (STFT), which maps a signal into the 2-D function of time and frequency (Gabor 1946). STFT represents both time and frequency of the signal. The window size can vary according to signal length to determine the time and frequency more accurately. Two types of Wavelet transform, such as Continuous Wavelet Transformations (CWT) and Discrete Wavelet Transformations (DWT), are used. DWT is more accurate than CWT because the transformation made by DWT does not show extra noise, which is not necessary for model evaluation. Based on Fourier analysis during signal processing of DWT, approximate coefficient produced by low pass filter and complex coefficient produced by high pass filter (Akrami et al. 2014). CWT forms an infinite number of wavelets, making it difficult to find desired results from transformed data. Using DWT, such difficulty does not occur because it calculates wavelet coefficients on discrete dyadic scales with time. Hence, DWT analysis is mainly preferred for forecasting problems of water resource systems because it needs short computational time. In DWT, the original signal is passed via low pass and high pass filters, followed by down-sampling using both filters after passing through the low pass and high pass filters. As a function of decomposition, the high pass filter followed by down-sampling information.

The low pass filter coupled with the scaling function which produces the information. Once the necessary level of breakdown has been reached, the decomposition procedure is repeated. The length of the data determines the maximum number of levels. Until the approximation coefficient

298 is split into a large number of smaller components, the process is repeated several times. In a 299 time-series signal, an approximate coefficient describes the general trend of the signal. In contrast, a detail coefficient represents the high-frequency components of the original time series signal (Seo et al. 2015). 
A wavelet is a small wave of limited duration with zero average value. The wavelet family

starts with orthogonal functions, namely scaling function $\emptyset_{(t)}$ and wavelet functions $\varphi_{(\mathrm{t})}$.

Wavelet function must have finite energy. The real-time data can be analyzed either by movement of Wavelet along the time axis at a different location called translation or by stretching and squeezing the Wavelet known as scale or dilation for data transformation.

Suppose you use the Down sampling with both filters' method. In that case, your signal $\mathrm{x}(\mathrm{n})$ travels through a low pass filter and a high pass filter before being downsampled using the low pass filter. High pass filter followed by downsampling created detail information $\mathrm{cD}(\mathrm{n})$. In contrast, low pass filters associated with scaling functions produced approximation information $\mathrm{cA}$ at the decomposition level (n). Once the necessary level of breakdown has been reached, the decomposition procedure is repeated. The length of the transmission determines the maximum number of levels. The process of iterating until the approximation coefficient is decomposed into several lower resolution components. At this point, the procedure is completed. The following criterion is satisfied by the decomposition of signal $\mathrm{x}(\mathrm{n})$ by DWT:

$x(n)=c D_{1}+c A_{1}=c D_{1}+c D_{2}+c A_{2}=c D_{1}+c D_{2}+c D_{3}+c A_{3}$ and so on $\ldots$

Standard wavelets used for wavelet analysis.The most significant advantage of employing wavelets is that they are spatially localized. These algorithms used for data compression, data processing, and the solution of differential equations. WNN models are constructed using the Haar wavelet in this study since it is the most straightforward, easily imagined, and historically earliest wavelet family. As an illustration, the following is the wavelet function of the Haar wavelet:

$\psi(x)=\left\{\begin{array}{c}1, \quad 0 \leq x<\frac{1}{2} \\ -1, \frac{1}{2} \leq x<1 \\ 0, \text { otherwise }\end{array}\right.$

The scaling function of the Haar wavelet is: 
$\psi(x)= \begin{cases}1, & 0 \leq x<1 \\ 0, & \text { otherwise }\end{cases}$

\subsection{Gamma Test}

The gamma test can be used to make decisions about selecting input data or inputs that affect the result of developed models. The gamma test, in general, is a multi-objective and unbiased technique for determining the substantial effect of each input variable. The gamma test was first introduced by Stefánsson et al., (1997), and it was later utilized by other researchers (Remesan et al. 2009; Kakaei Lafdani et al. 2013; Malik et al. 2017). The gamma test is used to determine whether continuous non-linear models have the minimum standard error for each set of inputoutput data. The number of inputs was chosen depending on the gamma $(\Gamma)$ and V-ratio of the system. Using continuous non-linear models, the gamma test can estimate the minimum standard error for each pair of input-output data sets. Consider the following representation of a data sample:

$\left\{x_{i}(i), \ldots . x_{m}(i), y_{i}\right\}=\left\{x_{i}, y_{i}\right\}[1 \leq 1 \leq M]$

The input variables $x_{i}, \ldots . x_{m}$ are referred to as the inputs vector; the number of input variables is $\mathrm{m}$; the number of related outputs is $y_{i}$, and $M$ is the number of patterns. To compute the gamma coefficient $(\Gamma)$, a linear regression line between the input $(X)$ and the output $(Y)$ is constructed as follows:

$y=f\left(X_{i}, \ldots \ldots X_{m}\right)+\Gamma$

Here $f=$ smooth function, and $\Gamma=$ random variable denoting noise. The result $\mathrm{Y}$ from Eq. 19 gives helpful information regarding how the model's complexity has been increased or decreased. If the value is near zero, we have input parameters that are more appropriate for the situation. Increasing the gradient implies that we have a more intricate model; conversely, decreasing the gradient shows that we have a simpler model. In general, a smaller standard error (SE) of a gamma value indicates a more dependable gamma result. The predictability of variable (target) is shown by the V-ratio calculated by Eq. 21 . 
$V_{\text {ratio }}=\frac{\Gamma}{\sigma^{2}(y)}$

345 Where $\sigma^{2}(y)=$ output variance of $y$, gamma $(\Gamma)=$ the gamma function. It is represent higher 346 degree of predictability if If $\mathrm{V}$-ratio is close to 0 . In situations where the V-ratio is near zero, we 347 have a better degree of predictability. Suppose the values of gamma, gradient, SE, and V-ratio are smaller. In that case, we will be able to create a high-quality mathematical model. As part of this study, the most influential input combinations (variables) were selected based on their lowest value of $\Gamma$, SE, and V-ratios(J. et al. 2009; Malik et al. 2017) to evaluate their influence on the stage-discharge modeling, from which meaningful combinations are derived. The gamma test was carried out in this study with the help of the winGamma software.

\subsection{Model performance evaluation indices}

The Pearson correlation coefficient (PCC), Nash-Sutcliffe efficiency (CE), root mean squared error (RMSE), Willmott Index (WI), and coefficient of determination $\left(\mathrm{R}^{2}\right)$ were used to evaluate the effectiveness of the designed models.

$$
\begin{aligned}
& P C C=\left(\frac{\sum_{i=1}^{N}\left(O_{i}-\bar{O}\right)\left(P_{i}-\bar{P}\right)}{\left(\sqrt{\left(\sum_{i=1}^{N}\left(O_{i}-\bar{O}\right)^{2}\right)\left(\sum_{i=1}^{N}\left(P_{i}-\bar{P}\right)^{2}\right)}\right)}\right)^{2}(-1<P C C<1) \\
& R M S E=\left(\frac{1}{n}\left(O_{i}-P_{i}\right)\right)^{0.5}(0<R M S E<\infty) \\
& W I=1-\frac{\sum_{i=1}^{N}\left(O_{i}-P_{i}\right)^{2}}{\sum_{i=1}^{N}\left(\left|P_{i}-\bar{O}\right|+\left|O_{i}-\bar{O}\right|\right)^{2}}(0<W I \leq 1) \\
& C O E=1-\left(\frac{\sum_{i=1}^{N}\left(O_{i}-P_{i}\right)^{2}}{\sum_{i=1}^{N}\left(O_{i}-\bar{P}\right)^{2}}\right)(-\infty<C O E<1)
\end{aligned}
$$


ANN, ANFIS, and WANN have been executed in the present investigation to anticipate the daily

360 discharge from the Gaula barrage site situated at Kathgodam near Haldwani (Nainital)

361 Uttarakhand, India. The outcomes demonstrated that the wavelet-based model could foresee high

362 and low peak discharges, utilizing multi-scale time arrangements. In this manner, in the current

363 study, the daily wise data of stage and discharge during the years were considered to advance

364 models. Table 1 shows the year-by-year statistics for stage and discharges with a time lag and lag

365 between stages.

366 Table1. Pairs in training and testing for stage-discharge models (Input-output)

\begin{tabular}{|c|c|c|c|c|c|c|c|}
\hline \multirow{3}{*}{$\begin{array}{l}\text { Year } \\
\text { (i) }\end{array}$} & \multirow{3}{*}{$\begin{array}{l}\text { Days } \\
\text { (j) }\end{array}$} & \multicolumn{5}{|c|}{ Input for $j^{\text {th }}$ day } & \multirow{2}{*}{$\begin{array}{l}\text { Output } \\
\mathbf{Y}\end{array}$} \\
\hline & & $\overline{\mathbf{X}_{1}}$ & $\overline{\mathbf{X}_{2}}$ & $\overline{\mathbf{X}_{3}}$ & $\overline{X_{4}}$ & $\overline{X_{5}}$ & \\
\hline & & $\overline{H_{i, j-2}}$ & $H_{i, j-1}$ & $\mathbf{H}_{\mathrm{i}, \mathrm{j}}$ & $\overline{Q_{i, j-2}}$ & $\mathbf{Q}_{\mathrm{i}, \mathrm{j}-1}$ & $\overline{\mathbf{Q}_{\mathrm{i}, \mathrm{j}}}$ \\
\hline \multirow{5}{*}{1} & 3 & $\overline{\mathrm{H}_{1,1}}$ & $\overline{\mathrm{H}_{1,2}}$ & $\mathrm{H}_{1,3}$ & $\overline{\mathrm{Q}_{1,1}}$ & $\overline{\mathrm{Q}_{1,2}}$ & $\overline{\mathrm{Q}_{1,3}}$ \\
\hline & 4 & $\mathrm{H}_{1,2}$ & $\mathrm{H}_{1,3}$ & $\mathrm{H}_{1,4}$ & $\mathrm{Q}_{1,2}$ & $\mathrm{Q}_{1,3}$ & $\mathrm{Q}_{1,4}$ \\
\hline & 5 & $\mathrm{H}_{1,3}$ & $\mathrm{H}_{1,4}$ & $\mathrm{H}_{1,5}$ & $\mathrm{Q}_{1,3}$ & $\mathrm{Q}_{1,4}$ & $\mathrm{Q}_{1,5}$ \\
\hline & $\ldots$ & $\ldots$ & $\ldots$ & $\ldots$ & $\ldots$ & $\ldots$ & $\ldots$ \\
\hline & 122 & $\mathrm{H}_{1,120}$ & $\mathrm{H}_{1,121}$ & $\mathrm{H}_{1,122}$ & $\mathrm{Q}_{1,120}$ & $\mathrm{Q}_{1,121}$ & $\mathrm{Q}_{1,122}$ \\
\hline \multirow{5}{*}{2} & 3 & $\mathrm{H}_{2,1}$ & $\mathrm{H}_{2,2}$ & $\mathrm{H}_{2,3}$ & $\mathrm{Q}_{2,1}$ & $\mathrm{Q}_{2,2}$ & $\mathrm{Q}_{2,3}$ \\
\hline & 4 & $\mathrm{H}_{2,2}$ & $\mathrm{H}_{2,3}$ & $\mathrm{H}_{2,4}$ & $\mathrm{Q}_{2,2}$ & $\mathrm{Q}_{2,3}$ & $\mathrm{Q}_{2,4}$ \\
\hline & 5 & $\mathrm{H}_{2,3}$ & $\mathrm{H}_{2,4}$ & $\mathrm{H}_{2,5}$ & $\mathrm{Q}_{2,3}$ & $\mathrm{Q}_{2,4}$ & $\mathrm{Q}_{2,5}$ \\
\hline & $\ldots$ & $\ldots$ & $\ldots$ & $\ldots$ & $\ldots$ & $\ldots$ & $\ldots$ \\
\hline & 122 & $\mathrm{H}_{2,120}$ & $\mathrm{H}_{2,121}$ & $\mathrm{H}_{2,122}$ & $\mathrm{Q}_{2,120}$ & $\mathrm{Q}_{2,121}$ & $\mathrm{Q}_{2,122}$ \\
\hline \multirow[t]{2}{*}{.. } & $\ldots$ & $\ldots$ & $\ldots$ & $\ldots$ & ... & $\ldots$ & $\ldots$ \\
\hline & 3 & $\mathrm{H}_{12,1}$ & $\mathrm{H}_{12,2}$ & $\mathrm{H}_{12,3}$ & $\mathrm{Q}_{12,1}$ & $\mathrm{Q}_{12,2}$ & $\mathrm{Q}_{12,3}$ \\
\hline \multirow[t]{2}{*}{12} & 4 & $\mathrm{H}_{12,2}$ & $\mathrm{H}_{12,3}$ & $\mathrm{H}_{12,4}$ & $\mathrm{Q}_{12,2}$ & $\mathrm{Q}_{12,3}$ & $\mathrm{Q}_{12,4}$ \\
\hline & 5 & $\mathrm{H}_{12,3}$ & $\mathrm{H}_{12,4}$ & $\mathrm{H}_{12,5}$ & $\mathrm{Q}_{12,3}$ & $\mathrm{Q}_{12,4}$ & $\mathrm{Q}_{12,5}$ \\
\hline
\end{tabular}




\begin{tabular}{cllllll}
\hline$\ldots$ & $\ldots$ & $\ldots$ & $\ldots$ & $\ldots$ & $\ldots$ & $\ldots$ \\
122 & $\mathrm{H}_{12,120}$ & $\mathrm{H}_{12,121}$ & $\mathrm{H}_{12,122}$ & $\mathrm{Q}_{12,120}$ & $\mathrm{Q}_{12,121}$ & $\mathrm{Q}_{12,122}$ \\
\hline
\end{tabular}

This work used MATLAB software to train and test feed-forward MLP based ANN and WANN models, which were then used to analyze the results. Table 2 lists the various training variables and the values assigned to them used for the development of ANN and WANN models during stage-discharge modelling in MATLAB and the values assigned to them.

Table 2. ANN and WANN models training variables and their assigned values

\section{Training variables}

Neural network type

Number of inputs

Number of outputs

Number of hidden layers

Number of processing element/neurons in hidden layer

Training function/Learning rule

Activation function in hidden layer

Maximum epoch

\section{Assigned values}

Feed forward Multilayer perceptron 3

1

1

1 to $2 \mathrm{n}+1$

Levenberg-Marquardt (LM)

Hyperbolic tangent sigmoid

1000

374 With the help of a hybrid learning method and the TSK (fuzzy inference) system, several ANFIS models were created in MATLAB software. MATLAB software is used to train ANFIS models for stage-discharge modeling. Table 3 lists the various training variables and the values assigned

377 to them throughout the training process. It is primarily through grid partition and subtractive 378 clustering that the FIS structure is produced. Jang (1993) proposed the use of grid partitioning for 379 the solution of problems with fewer than six input variables in order to save time. To construct the ANFIS structure in this work, the grid partition method of FIS generation was employed. 
Table 3 ANFIS models (training variables and their assigned values)

\begin{tabular}{ll}
\hline Training variables & Assigned value \\
\hline FIS generation method & Grid partition \\
FIS Type & TSK \\
Number of membership function per input & 2,3 \\
Types of input MFs & Gaussmf, Trimf, Gbellmf, Psigmf \\
Types of output MFs & Linear \\
Epoch & 100 \\
Error tolerance & 0.001 \\
Learning algorithm & Hybrid
\end{tabular}

\subsection{Development of Models stage-discharge modeling}

Different ANN models were developed for hydrological modeling using daily (stage) and discharge data during monsoon season to predict daily discharge in the Gaula river basin. The observed time series of current-day and preceding days lag were taken as input variables and recent day discharge as the output variable, taking into account the monsoon season starting from $1^{\text {st } J u n e ~ t o ~} 30^{\text {th }}$ September only. In this case, $N=122$ days ( $1_{\text {st }}$ June to 30 th September) in a year and $\mathrm{M}=12$ years (2007-2018). Let the observed values of stage and discharge be represented as $H_{i, j}$ and $Q_{i, j}$ respectively for the $j^{\text {th }}$ day of the $i^{\text {th }}$ year $(i=1,2,3 \ldots \ldots \ldots$ and $j=1,2,3 \ldots \ldots . \mathrm{N})$ and $\mathrm{m}$ standards for time lag which are taken as two in the present study. The functional form of the ANN model can be represented by Eq. 25 .

$\mathrm{Q}_{\mathrm{t}}=f\left(\mathrm{H}_{\mathrm{t}}, \mathrm{Q}_{\mathrm{t}-1}, \mathrm{Q}_{\mathrm{t}-2}\right)$

The daily hydrological data was used for stage-discharge prediction and development of ANFIS models. As the estimation of regular discharge is a complex and dynamic process, it requires a suitable time lag for its simulation. Therefore, various combinations of stage and discharge (i.e., 
stage of the current day, the preceding day, preceding two days and discharge of preceding day, preceding two days) as input and discharge of current day as output was used in discharge estimation and can be functionally expressed as Eq. (26).

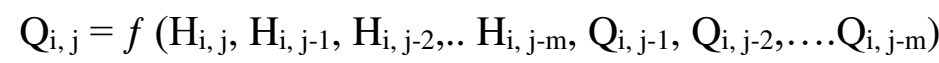

In Wavelet-based ANN models for stage-discharge modeling, the observed time series of stage and discharge data is resolved at three-level using Haar a trous algorithm, and the transformed time series of stage and discharge is used as input variables instead of original time series; however, all other resolved parameters were taken in their original form. The decomposed components of time series by DWT like $\mathrm{H}_{\mathrm{Di}}(\mathrm{t}), \ldots \ldots, \mathrm{H}_{\mathrm{Di}}(\mathrm{t}-\mathrm{n}), \mathrm{H}_{\mathrm{Ai}}(\mathrm{t}), \ldots, \mathrm{H}_{\mathrm{Ai}}(\mathrm{t}-\mathrm{n})$ and $\mathrm{Q}_{\mathrm{Di}}(\mathrm{t}-1) \ldots$, $\mathrm{Q}_{D i}(\mathrm{t}-\mathrm{n}), \mathrm{Q}_{\mathrm{Ai}}(\mathrm{t}-1) \ldots, \mathrm{Q}_{\mathrm{Ai}}(\mathrm{t}-\mathrm{n})$ were used for stage-discharge modelling. Where $\mathrm{H}_{\mathrm{Di}}(\mathrm{t}) \ldots, \mathrm{H}_{\mathrm{Di}}(\mathrm{t}-\mathrm{n})$, and $\mathrm{H}_{\mathrm{Ai}}(\mathrm{t}) \ldots, \mathrm{H}_{\mathrm{Ai}}(\mathrm{t}-\mathrm{n})$ is the detailed and approximated sub-signals of stage time series, respectively. Here, $D_{i}$ represents detail sub-signal decomposed at the $i^{\text {th }}$ level. $A_{i}$ represents approximated sub-signal decomposed at the $\mathrm{i}^{\text {th }}$ level. Then, the decomposed stage $(\mathrm{H})$ and discharge (Q) sub-time series at approximate levels (i) were fed as input to the ANN model to predict daily discharge. The functional form of the model is expressed by Eq. 27 .

$Q_{t}=f\left(H_{D 1}(t), \ldots, H_{D i}(t), H_{A i}(t-n) \ldots, H_{D i}(t-n), H_{A i}(t-n), Q_{D 1}(t-\right.$

$\left.n), \ldots, Q_{D i}(t-n), Q_{A i}(t-n)\right)$

\section{Results and Discussions}

Stage-discharge modeling for Gaula barrage site located in Gaula river, twelve years daily data of stage $(\mathrm{H})$ and discharge $(\mathrm{Q})$ of monsoon season from June to September were used for analysis. The data was divided into two parts: training data for calibration of the models and testing data to validate the models. Training data was used to calibrate the models, and testing data was used to validate the models. The models' performance was evaluated qualitatively through visual observation and quantitatively through the use of different statistical and hydrological criteria, including RMSE, $\mathrm{R}^{2}$, WI and CE. 
419

420

421

422

423

The statistical parameters such as mean, median ( minimum and maximum value), standard deviation (Std. Dev), skewness for the stage (H), coefficient of variation (CV) and discharge (Q) datasets for training, testing, and the entire period, is summarized Table 4. These statistical parameters represent the variability of data across time. In order to have the same statistical population in training and testing subsets and required cross-validate the data. The high skewness coefficient has had a significant detrimental impact on the model's performance, as has been demonstrated. This station's calibrated and validated skewness coefficients are low, as shown by the low skewness coefficients for both the calibration and validation coefficients for the stated station.

\subsection{Model input variable selection using gamma test}

When dealing with non-linear models, the selection of model inputs is a critical and challenging topic. In the current study, different input combinations (Table 5) were created and studied to assess how they influenced the stage $(\mathrm{H})$ - discharge $(\mathrm{Q})$ at the Gaula barrage site. In Table 5, $\mathrm{H}_{t-}$ $1, \mathrm{H}_{t-2}, \mathrm{Q}_{t-1}$, and $\mathrm{Q}_{t-2}$ are the stage and discharge values of previous one $(t-1)$ and two $(t-2)$ days. The gamma test method was conducted to test which input variables were most efficient for the ANN, ANFIS, and WANN models. Table 5 contains the results of the tests. Table 5 Clearly, models 24 with mask 11,001 provide the smallest values for many parameters such as gradient gamma value $(\Gamma)$, standard error $(\mathrm{SE})$, and $\mathrm{V}$-ratio. The mask specifies the number of active input variables that are being used at any given moment; for example, mask 11,001 indicates that a total of eleven input variables are being used at the same time to produce an output, i.e., discharge. Model numbers 24 and 12 were chosen for further investigation out of 31 possible combinations. 
Table 4. Statistics of discharge, stage and variables during during study Station.

\begin{tabular}{|c|c|c|c|c|c|c|}
\hline \multirow[b]{2}{*}{ Statistical Parameter } & \multicolumn{2}{|l|}{ Training } & \multicolumn{2}{|l|}{ Testing } & \multicolumn{2}{|l|}{ Entire } \\
\hline & $\begin{array}{l}\boldsymbol{H} \\
(\mathbf{m})\end{array}$ & $\begin{array}{l}Q \\
\left(\mathrm{ft}^{3} / \mathrm{sec}\right)\end{array}$ & $\begin{array}{l}\boldsymbol{H} \\
(\mathbf{m})\end{array}$ & $\begin{array}{l}Q \\
\left(\mathrm{ft}^{3} / \mathrm{sec}\right)\end{array}$ & $\begin{array}{l}H \\
(\mathbf{m})\end{array}$ & $\begin{array}{l}Q \\
\left(\mathrm{ft}^{3} / \mathrm{sec}\right)\end{array}$ \\
\hline Mean & 24.022 & 40.510 & 18.540 & 37.665 & 22.296 & 39.824 \\
\hline Median & 80.000 & 135.000 & 85.000 & 147.000 & 85.000 & 135.000 \\
\hline Minimum & 0.000 & 0.000 & 0.000 & 0.000 & 0.000 & 0.000 \\
\hline Maximum & 885.000 & 184.000 & 100.000 & 184.000 & 885.000 & 184.000 \\
\hline Standard deviation & 44.922 & 48.925 & 25.004 & 47.844 & 39.851 & 48.958 \\
\hline Coefficient of variance & 56.153 & 36.241 & $127.023^{`}$ & 134.868 & 178.736 & 122.935 \\
\hline Skewness & 7.361 & -1.144 & -1.733 & -1.245 & 7.181 & -1.151 \\
\hline
\end{tabular}


Table 5. Selection of the best input combination for stage-discharge modelling using Gamma test.

\begin{tabular}{|c|c|c|c|c|c|}
\hline Model No. & Model Input Combination & Mask & Gamma value & V-ratio & Standard Error \\
\hline M1 & $\mathbf{H}_{(\mathbf{t})}$ & 00001 & -0.0035505 & -0.0042018 & 0.0488806 \\
\hline M2 & $\mathbf{Q}_{(\mathrm{t}-1)}$ & 01000 & 0.2172343 & 0.8689372 & 0.1207246 \\
\hline M3 & $\mathbf{H}_{(\mathrm{t}-1)}$ & 00010 & 0.0996951 & 0.3987803 & 0.1371814 \\
\hline M4 & $\mathbf{H}_{(\mathrm{t}-2)}$ & 00100 & 0.2223312 & 0.8893246 & 0.1230553 \\
\hline M5 & $\mathbf{Q}_{(\mathrm{t}-2)}$ & 10000 & 0.1990454 & 0.7961815 & 0.1364132 \\
\hline M6 & $\mathbf{H}_{(\mathrm{t})}, \mathbf{Q}_{(\mathrm{t}-1)}$ & 10010 & -0.0061830 & -0.0247321 & 0.0096368 \\
\hline M7 & $\mathbf{H}_{(\mathrm{t})}, \mathbf{Q}_{(\mathrm{t}-2)}$ & 10001 & -0.0083674 & -0.0334697 & 0.0082618 \\
\hline M8 & $\mathbf{H}_{(\mathrm{t})}, \mathbf{H}_{(\mathrm{t}-1)}$ & 00011 & -0.0037797 & -0.0151188 & 0.0062380 \\
\hline M9 & $\mathbf{H}_{(t)}, \mathbf{H}_{(t-2)}$ & 00101 & -0.0068699 & -0.0274797 & 0.0066910 \\
\hline M10 & $\mathbf{Q}_{(\mathrm{t}-1)}, \mathbf{H}_{(\mathrm{t}-2)}$ & 01100 & 0.1444147 & 0.5776588 & 0.0159508 \\
\hline M11 & $\mathbf{Q}_{(\mathrm{t}-1)}, \mathbf{H}_{(\mathrm{t}-1)}$ & 01010 & 0.1432440 & 0.5729759 & 0.1291274 \\
\hline M12 & $\mathbf{Q}_{(\mathrm{t}-2)}, \mathbf{H}_{(\mathrm{t}-1)}$ & 10010 & 0.1125862 & 0.4503450 & 0.0255596 \\
\hline M13 & $\mathbf{Q}_{(\mathrm{t}-2)}, \mathbf{H}_{(\mathrm{t}-2)}$ & 10100 & 0.1850115 & 0.7400460 & 0.1142124 \\
\hline M14 & $\mathbf{H}_{(\mathrm{t}-1)}, \mathbf{H}_{(\mathrm{t}-2)}$ & 00110 & 0.1491141 & 0.5964564 & 0.0277311 \\
\hline
\end{tabular}




\begin{tabular}{|c|c|c|c|c|c|}
\hline M15 & $\mathbf{H}_{(\mathrm{t}-2)}, \mathbf{Q}_{(\mathrm{t}-2)}, \mathbf{H}_{(\mathrm{t}-1)}$ & 10110 & 0.0978218 & 0.3912870 & 0.0259878 \\
\hline M16 & $\mathbf{H}_{(\mathrm{t}-2)}, \mathbf{Q}_{(\mathrm{t}-2)}, \mathbf{Q}_{(\mathrm{t}-1)}$ & 11100 & 0.1062280 & 0.4249120 & 0.0252639 \\
\hline M17 & $\mathbf{H}_{(\mathrm{t}-1)}, \mathbf{H}_{(\mathrm{t}-\mathrm{2})}, \mathbf{Q}_{(\mathrm{t}-1)}$ & 01110 & 0.1473661 & 0.5894643 & 0.0139836 \\
\hline M18 & $\mathbf{Q}_{(\mathrm{t}-1)}, \mathbf{Q}_{(\mathrm{t}-2)}, \mathbf{H}_{(\mathrm{t}-1)}$ & 11010 & 0.1171521 & 0.4686083 & 0.0230245 \\
\hline M19 & $\mathbf{H}_{(\mathrm{t})}, \mathbf{Q}_{(\mathrm{t}-2)}, \mathbf{H}_{(\mathrm{t}-2)}$ & 10101 & -0.0102464 & -0.0409856 & 0.0114874 \\
\hline M20 & $\mathbf{H}_{(t)}, \mathbf{H}_{(t-1)}, \mathbf{H}_{(t-2)}$ & 00111 & -0.0059118 & -0.0236473 & 0.0075705 \\
\hline M21 & $\mathbf{H}_{(\mathrm{t})}, \mathbf{H}_{(\mathrm{t}-1)}, \mathbf{Q}_{(\mathrm{t}-2)}$ & 10011 & -0.0068414 & -0.0273657 & 0.0075121 \\
\hline M22 & $\mathbf{H}_{(\mathrm{t})}, \mathbf{H}_{(\mathrm{t}-1)}, \mathbf{Q}_{(\mathrm{t}-1)}$ & 01011 & -0.0087202 & -0.0348808 & 0.0092684 \\
\hline M23 & $\mathbf{H}_{(\mathbf{t})}, \mathbf{H}_{(\mathrm{t}-2)}, \mathbf{Q}_{(\mathrm{t}-1)}$ & 01101 & -0.0031104 & -0.0124416 & 0.0043302 \\
\hline M24 & $\mathbf{H}_{(\mathrm{t})}, \mathbf{Q}_{(\mathrm{t}-2)}, \mathbf{Q}_{(\mathrm{t}-1)}$ & 11001 & -0.0114180 & -0.0456721 & 0.0089775 \\
\hline M25 & $\mathbf{Q}(\mathrm{t}-1), \mathbf{Q}_{(\mathrm{t}-2)}$ & 11000 & 0.1188092 & 0.4752367 & 0.0235302 \\
\hline M26 & $\mathbf{H}_{(\mathrm{t})}, \mathbf{H}_{(\mathrm{t}-2)}, \mathbf{H}_{(\mathrm{t}-1)}, \mathbf{Q}_{(\mathrm{t}-1)}$ & 01111 & -0.0027419 & -0.0109675 & 0.0058150 \\
\hline M27 & $\mathbf{H}_{(\mathrm{t})}, \mathbf{H}_{(\mathrm{t}-2)}, \mathbf{H}_{(\mathrm{t}-1)}, \mathbf{Q}_{(\mathrm{t}-2)}$ & 10111 & -0.0052684 & -0.0210738 & 0.0074483 \\
\hline M28 & $\mathbf{H}_{(\mathrm{t})}, \mathbf{Q}_{(\mathrm{t}-1)}, \mathbf{Q}_{(\mathrm{t}-2)}, \mathbf{H}_{(\mathrm{t}-1)}$ & 11011 & -0.0087173 & -0.0348692 & 0.0078268 \\
\hline M29 & $\mathbf{H}_{(\mathrm{t})}, \mathbf{Q}_{(\mathrm{t}-1)}, \mathbf{Q}_{(\mathrm{t}-2)}, \mathbf{H}_{(\mathrm{t}-2)}$ & 11101 & -0.0040099 & -0.0160394 & 0.0064002 \\
\hline M30 & $\mathbf{H}_{(\mathrm{t}-1)}, \mathbf{H}_{(\mathrm{t}-2)}, \mathbf{Q}_{(\mathrm{t}-2)}, \mathbf{Q}_{(\mathrm{t}-1)}$ & 11110 & 0.1036413 & 0.4145651 & 0.0255454 \\
\hline M31 & $\mathbf{H}_{(t)}, \mathbf{H}_{(t-1)}, \mathbf{H}_{(t-2)}, \mathbf{Q}_{(t-2)}, \mathbf{Q}_{(t-1)}$ & 11111 & -0.0039276 & -0.0157103 & 0.0062793 \\
\hline
\end{tabular}


$H_{(t-1)} \quad$ : stage at previous day

$H_{(t-2)} \quad$ : stage at previous two days

$Q \quad$ : discharge at present time $\left(\mathrm{ft}^{3} / \mathrm{s}\right)$

$Q_{(t-1)} \quad:$ discharge at previous day $\left(f t^{3} / s\right)$

$Q_{(t-2)} \quad$ : discharge at precious two days $\left(f t^{3} / s\right)$ 


\subsection{Artificial neural networks (ANN) models for discharge prediction}

Qualitative performance was evaluated (graphically) by visual observation of time series and scatter plot of predicted discharge versus observed discharge. For the best-selected ANN-6 model, the observed and predicted discharge values were observed to be in close agreement with low and medium discharge values, as shown in Figs. 4-5. The $\mathrm{R}^{2}$ value of the selected model was observed to be 0.9690 and 0.9878 during training and testing, respectively .Using Tansig function in the hidden layer, pure line activation function in the output layer, and Levenberg-Marquardt learning algorithm, the single hidden layer networks having higher values of Pearson correlation coefficient (PCC), Willmott index (WI), coefficient of efficiency (COE) and lower value of root mean square error (RMSE) have been selected, as shown in Table 6. For training, the values of RMSE, PCC, WI, and COE range from 17.0685 to $4.57 \mathrm{ft}^{3} / \mathrm{sec}, 0.93$ to $0.98,0.92$ to 0.98 , and 0.87 to 0.96 , respectively. For testing, the value of RMSE, PCC, WI and COE ranges from 17.65 $\mathrm{ft}^{3} / \mathrm{s}$ to $4.25 \mathrm{ft}^{3} / \mathrm{s}, 0.95$ to $0.99,0.79$ to 0.96 and 0.86 to 0.99 . ANN-6 model with architecture (36-1) was observed to be the best model compared to others based on quantitative criteria of performance evaluation. RMSE, PCC, WI, and COE values of the selected ANN-6 model were observed to be $4.57 \mathrm{ft}^{3} / \mathrm{sec}, 0.98,0.98$, and 0.96 , respectively, during training $4.25 \mathrm{ft}^{3} / \mathrm{sec}, 0.99$, 0.96 , and 0.99 , respectively during testing. 
Table 6. Comparison of various ANN models to select the best model during training and testing periods.

\begin{tabular}{|c|c|c|c|c|c|c|c|c|c|}
\hline \multirow{2}{*}{ Model } & \multirow{2}{*}{ Architecture } & \multicolumn{4}{|l|}{ Training } & \multicolumn{4}{|l|}{ Testing } \\
\hline & & RMSE(ft ${ }^{3} /$ sec $)$ & $\overline{\text { PCC }}$ & WI & COE & RMSE(ft $\left.{ }^{3} / \mathrm{sec}\right)$ & $\overline{\text { PCC }}$ & WI & $\overline{\mathrm{COE}}$ \\
\hline ANN-1 & $3-1-1$ & 17.06 & 0.93 & 0.92 & 0.87 & 17.65 & 0.95 & 0.79 & 0.86 \\
\hline ANN-2 & $3-2-1$ & 4.76 & 0.99 & 0.97 & 0.99 & 7.84 & 0.98 & 0.93 & 0.97 \\
\hline ANN-3 & $3-3-1$ & 9.32 & 0.98 & 0.97 & 0.96 & 5.98 & 0.99 & 0.95 & 0.98 \\
\hline ANN-4 & $3-4-1$ & 9.59 & 0.98 & 0.96 & 0.96 & 8.91 & 0.98 & 0.92 & 0.96 \\
\hline ANN-5 & $3-5-1$ & 4.79 & 0.99 & 0.98 & 0.99 & 7.32 & 0.98 & 0.95 & 0.97 \\
\hline ANN-6 & $3-6-1$ & 4.57 & 0.98 & 0.98 & 0.96 & 4.25 & 0.99 & 0.96 & 0.99 \\
\hline ANN-7 & $3-7-1$ & 6.23 & 0.99 & 0.97 & 0.98 & 9.06 & 0.98 & 0.93 & 0.96 \\
\hline
\end{tabular}




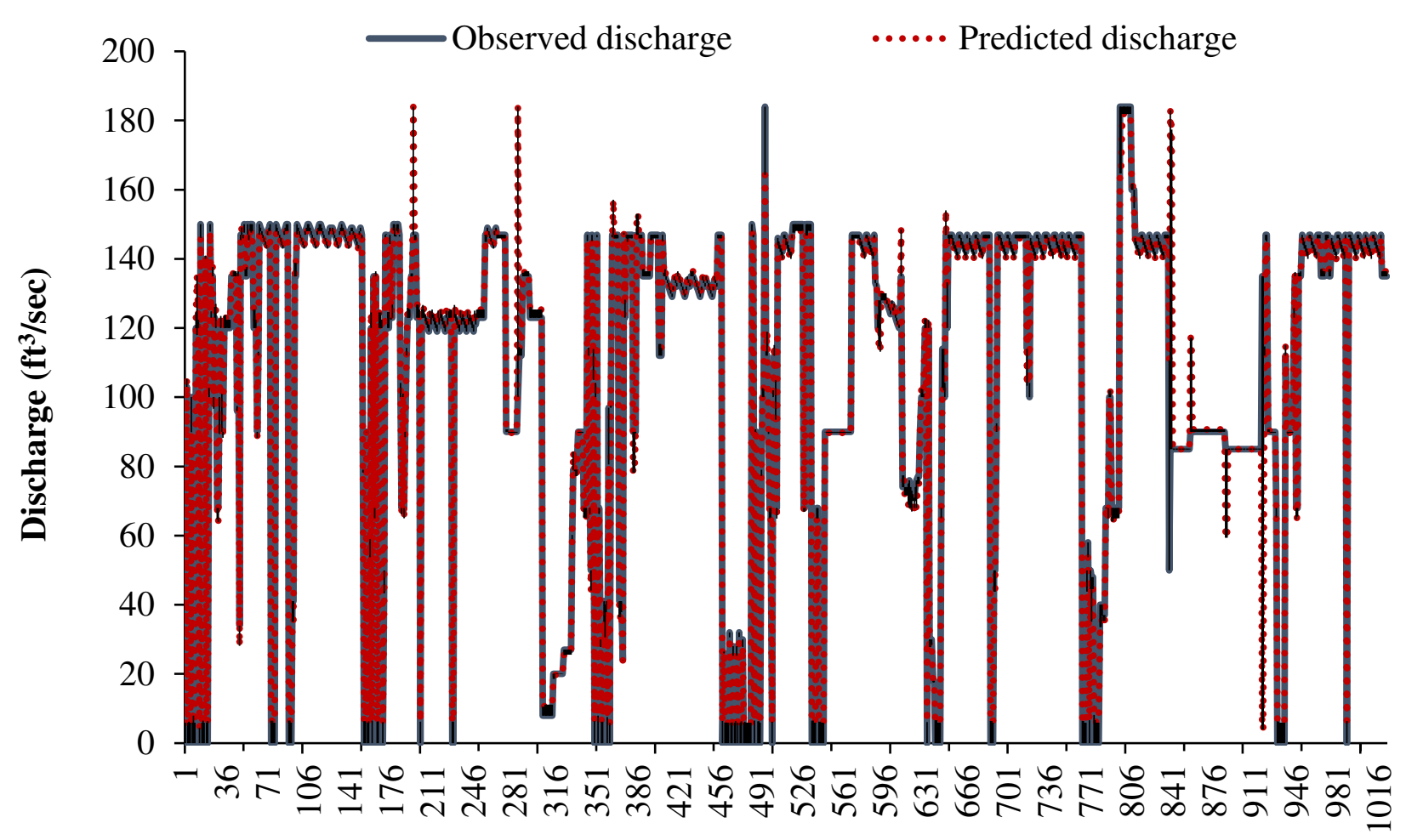

Time (Days)

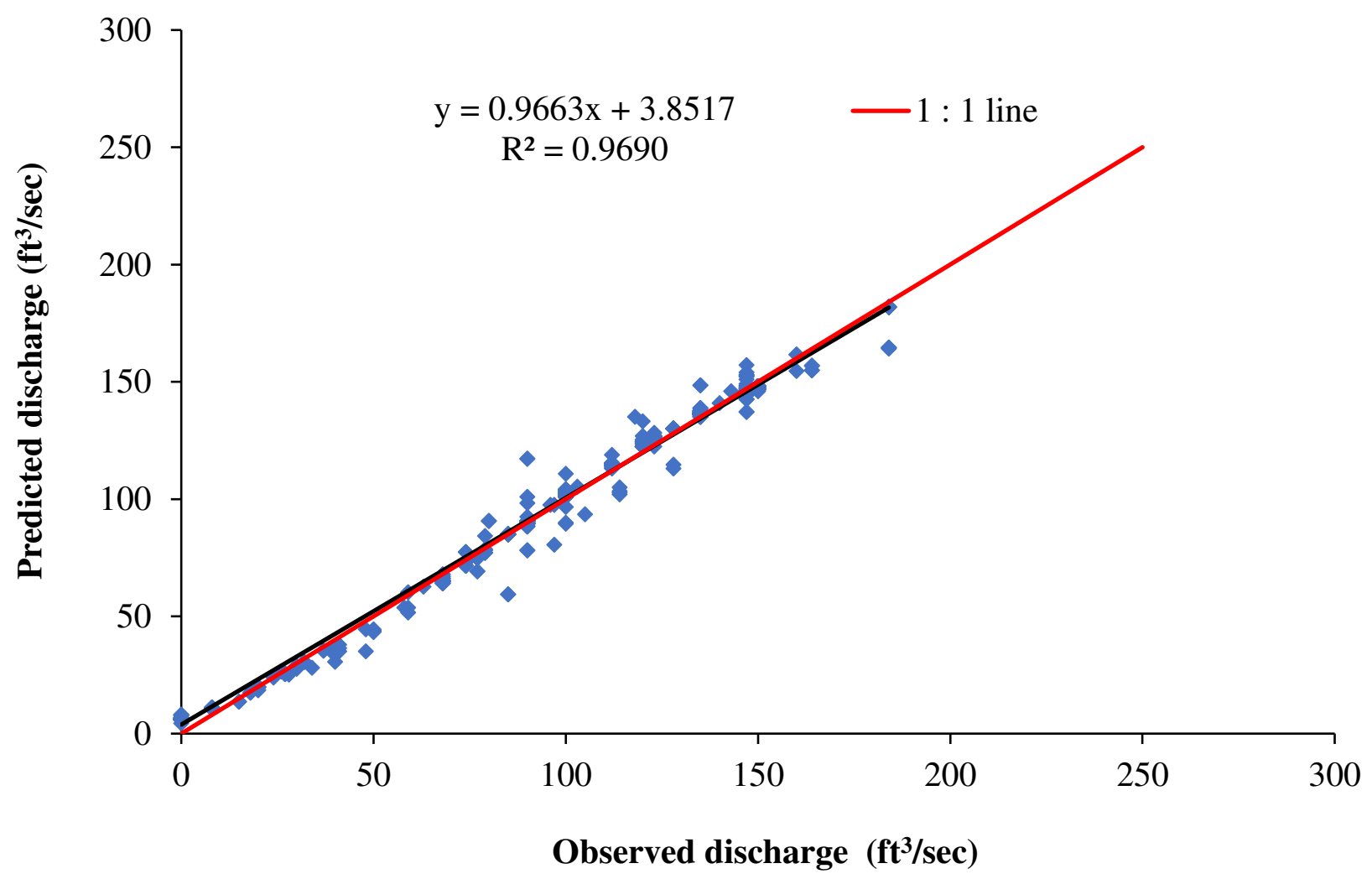

Fig. 4 Predicted and observed discharge and their corresponding scatter plot for ANN (3-6-1) model during training period $(01 / 06 / 2007$ to $18 / 07 / 2015)$ 


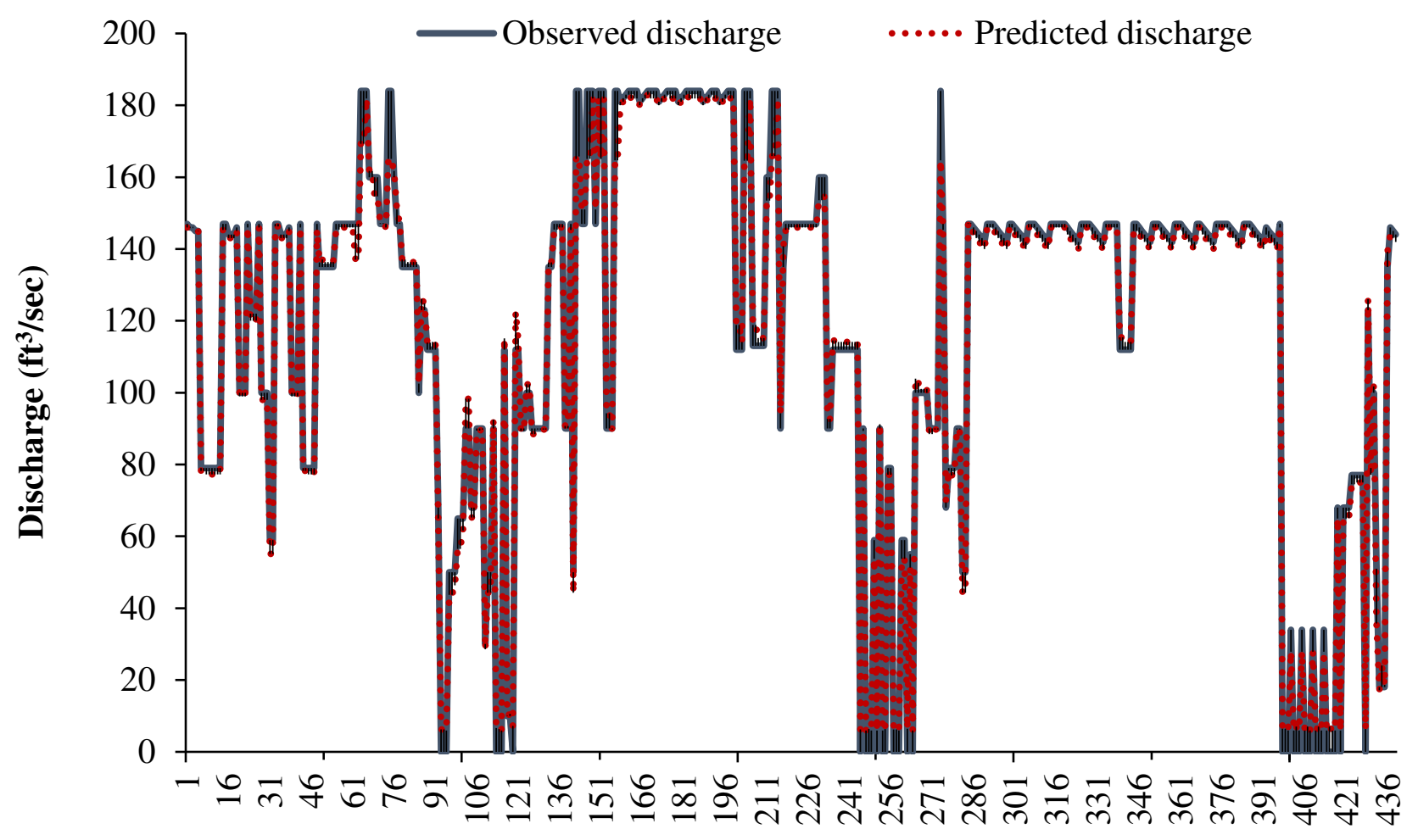

Time (Days)

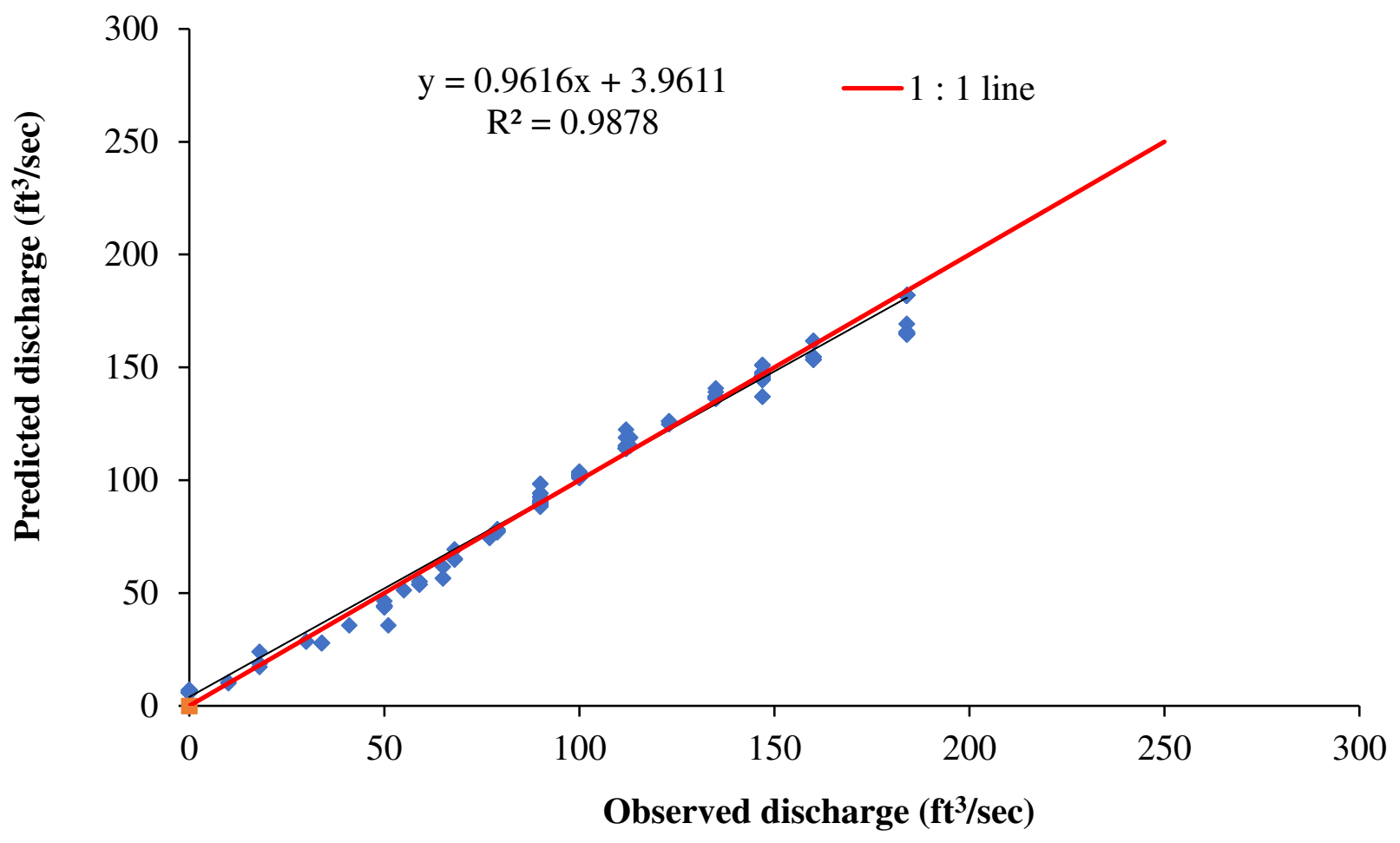

Fig. 5 Predicted and observed discharge and their corresponding scatter plot for ANN (3-6-1) model during testing period (19/07/2015 to 30/09/2018) 


\subsection{ANFIS models for discharge prediction}

Different ANFIS models for discharge prediction were developed using the ANFIS editor in MATLAB software with a hybrid learning algorithm. The grid partition method was used to build the ANFIS structure. Input membership functions like Triangular, p-sigmoidal, generalized bell, Gaussian, and output MF such as linear were used, varying the MF per input from 2 to 3. Rule base was prepared with OR logical operation by a varying number of rules from 2 to 3 . ANFIS models were formulated by keeping the error tolerance of 0.001 and epochs of 100 . Qualitatively, the observed and predicted discharge values of the selected ANFIS-08 model were found to be in close agreement with each other having an $\mathrm{R}^{2}$ value of 0.99 during training and 0.99 during testing, as shown in Figs. 6-7.

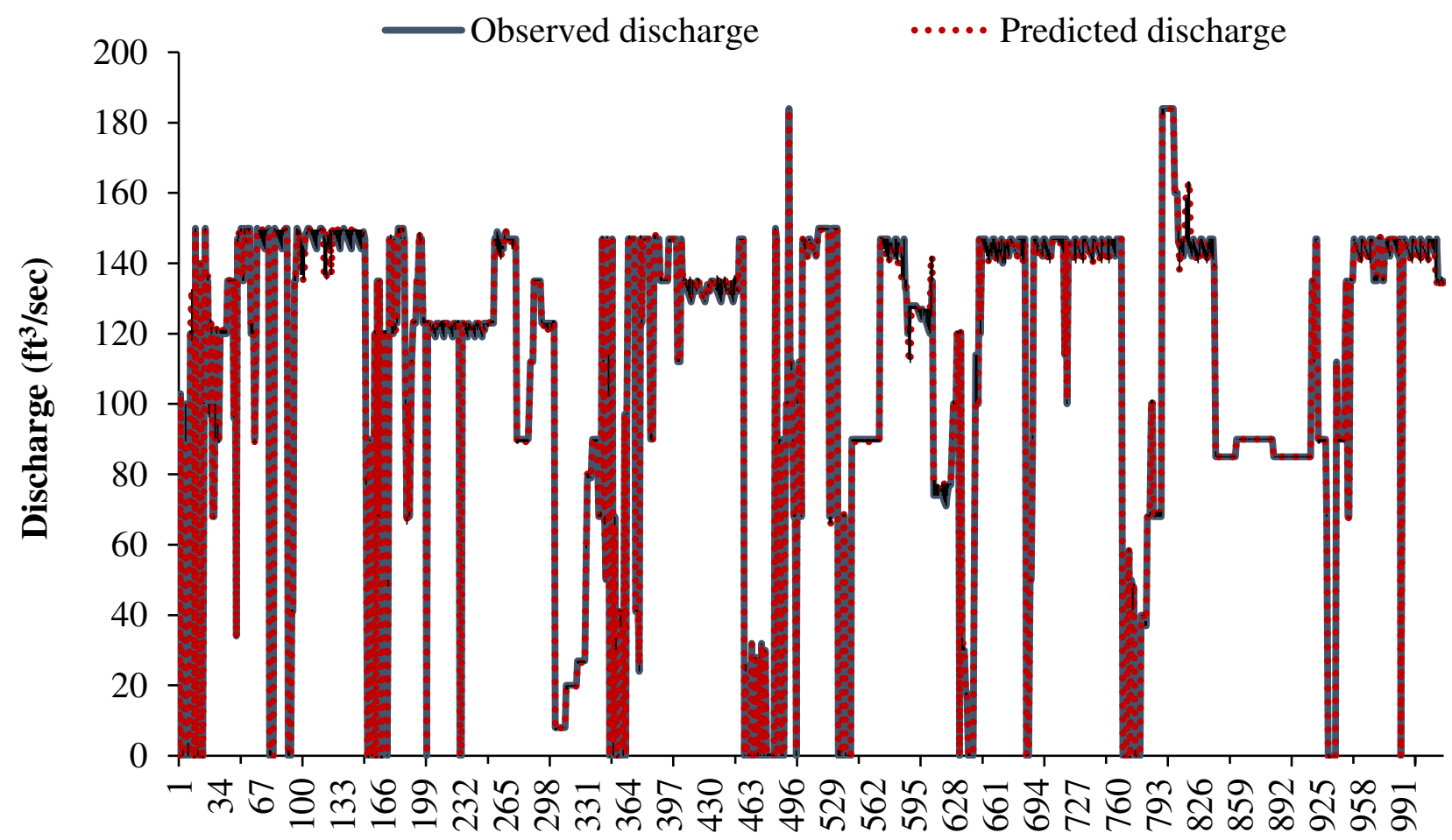

Time (Days) 


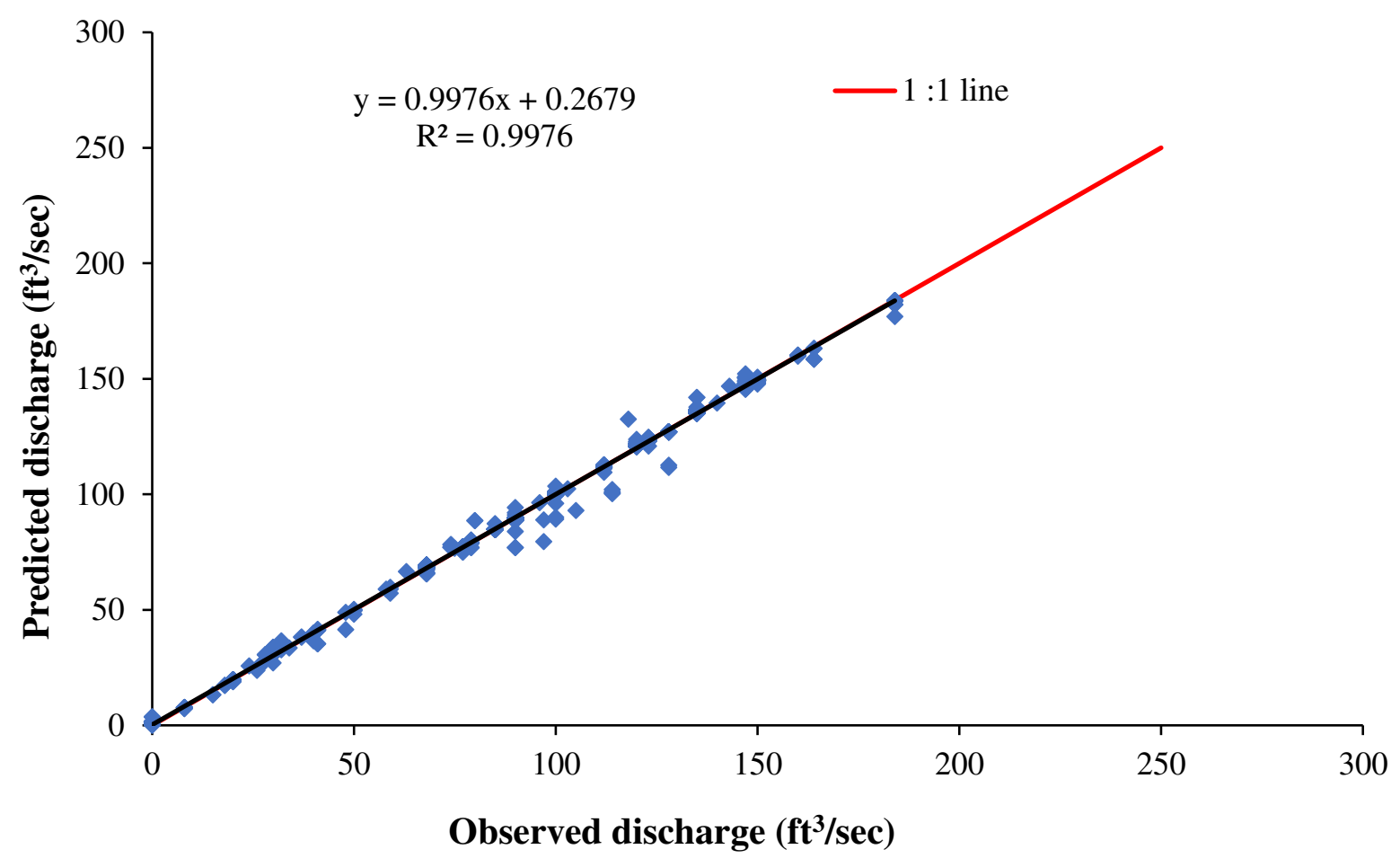

Fig. 6 Predicted and observed discharge and scatter plot for ANFIS-08 model during training period $(01 / 06 / 2007$ to $18 / 07 / 2015)$.

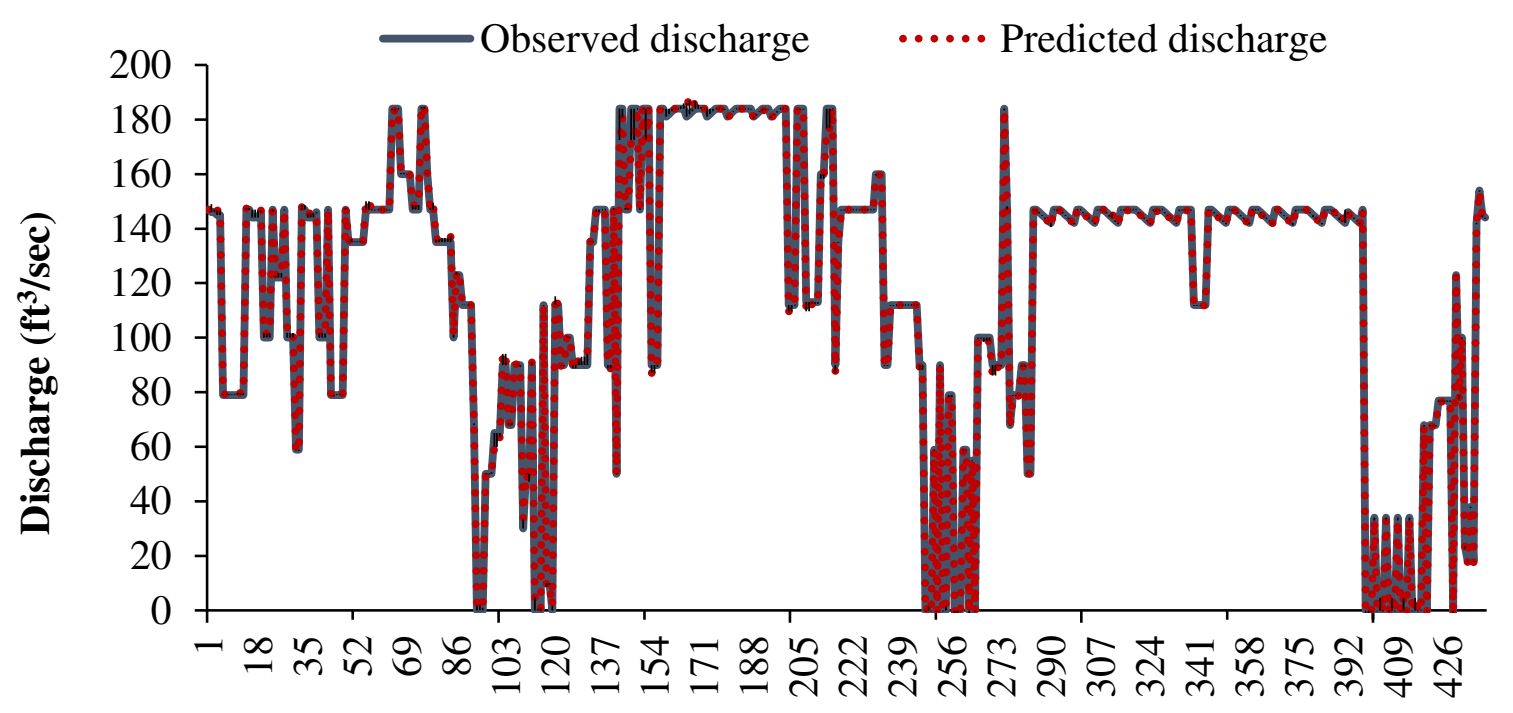

Time (Days) 


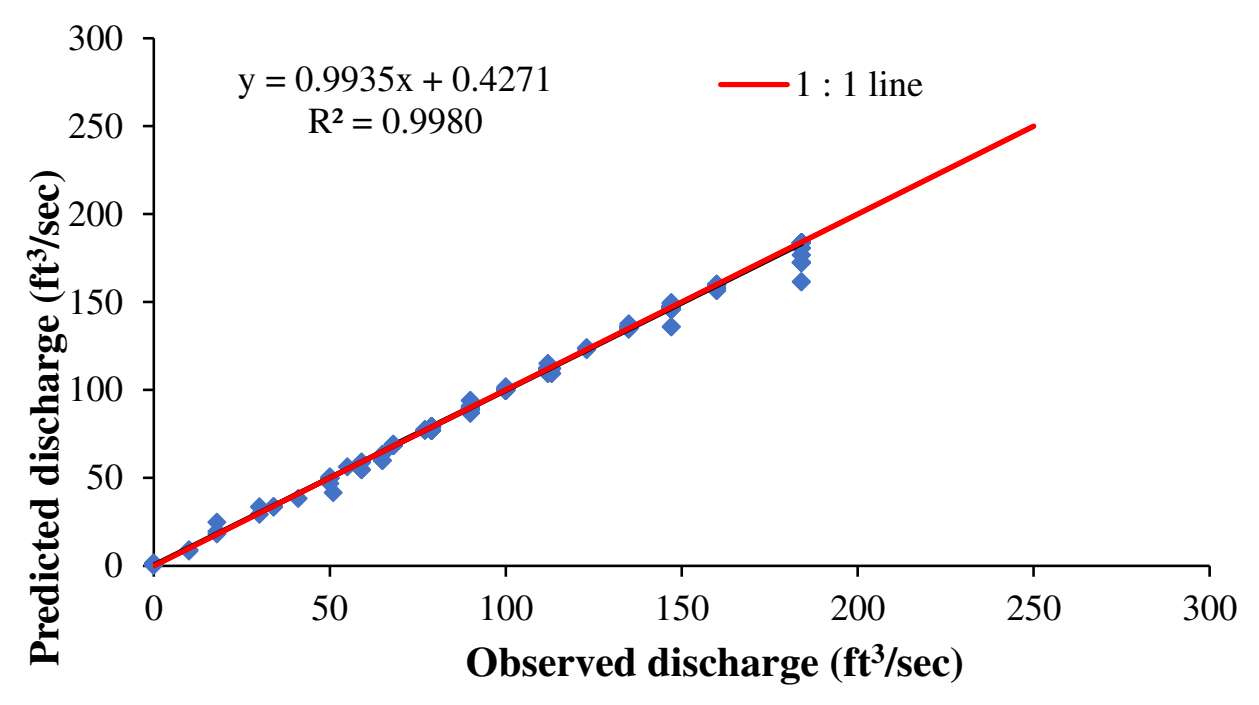

Fig.7 Predicted and observed discharge and their corresponding scatter plot for ANFIS-08 model during testing period $(19 / 07 / 2015$ to $30 / 09 / 2018)$

The results of different statistical and hydrological performance indicators of developed ANFIS models are presented in Table 7. It was revealed that RMSE, PCC, WI and COE values ranged from 2.38 to $7.16 \mathrm{ft}^{3} / \mathrm{sec}, 0.98$ to $0.99,0.97$ to 0.99 and 0.97 to 0.99 and 2.22 to $8.20 \mathrm{ft}^{3} / \mathrm{sec}, 0.98$ to $0.99,0.92$ to 0.98 and 0.97 to 0.99 during training and testing, respectively. It can see from Table 7 that all ANFIS models performed well during training. However, the ANFIS-08 model with Gaussian input MF, linear output MF, and 3 MFs per input performed well during training and testing based on quantitative performance evaluation criteria. RMSE, PCC, WI, and COE values of the selected ANFIS-08 model were observed to be $2.38 \mathrm{ft}^{3} / \mathrm{sec}, 0.99,0.99$, and 0.99 $2.22 \mathrm{ft}^{3} / \mathrm{sec}, 0.99,0.98$ and 0.99 during training and testing, respectively. 
Table 7 Comparison of various ANFIS models to select the best model during training and testing periods.

\begin{tabular}{|c|c|c|c|c|c|c|c|c|c|c|}
\hline \multirow{2}{*}{ MODEL } & \multirow{2}{*}{ Input MF } & \multirow{2}{*}{ MFs/Input } & \multicolumn{4}{|l|}{ Training } & \multicolumn{4}{|l|}{ Testing } \\
\hline & & & $\overline{R M S E}\left(\mathrm{ft}^{3} / \mathrm{sec}\right)$ & $\mathbf{r}$ & $\overline{\text { WI }}$ & $\overline{C E}$ & RMSE(ft $3 /$ sec $\left.^{3}\right)$ & $\mathbf{r}$ & $\overline{\text { WI }}$ & $\overline{C E}$ \\
\hline ANFIS-01 & Traingular & 2 & 6.2896 & 0.9916 & 0.9848 & 0.9833 & 3.6021 & 0.9973 & 0.9721 & 0.9944 \\
\hline ANFIS-02 & pSig & 2 & 7.1633 & 0.9891 & 0.9749 & 0.9783 & 8.2042 & 0.9863 & 0.9275 & 0.9712 \\
\hline ANFIS-03 & Generalised bell & 2 & 6.4251 & 0.9912 & 0.9801 & 0.9826 & 5.1714 & 0.9946 & 0.9562 & 0.9885 \\
\hline ANFIS-04 & Gaussian & 2 & 6.1298 & 0.9920 & 0.9827 & 0.9841 & 5.1627 & 0.9947 & 0.9583 & 0.9886 \\
\hline ANFIS-05 & Traingular & 3 & 5.7742 & 0.9929 & 0.9851 & 0.9859 & 4.9826 & 0.9948 & 0.9643 & 0.9894 \\
\hline ANFIS-06 & pSig & 3 & 2.4528 & 0.9987 & 0.9950 & 0.9975 & 2.3820 & 0.9985 & 0.9821 & 0.9950 \\
\hline ANFIS-07 & Generalised bell & 3 & 2.5447 & 0.9986 & 0.9953 & 0.9973 & 2.4920 & 0.9987 & 0.9891 & 0.9973 \\
\hline ANFIS-08 & Gaussian & 3 & 2.3823 & 0.9988 & 0.9949 & 0.9976 & 2.2230 & 0.9990 & 0.9897 & 0.9979 \\
\hline
\end{tabular}




\subsection{WANN model for daily discharge prediction}

Based on visual observations, the predicted and observed discharge values were in close agreement with each other during training and testing periods having $\mathrm{R}^{2}$ values of 0.9910 and 0.9880, as shown in Fig.8-9.

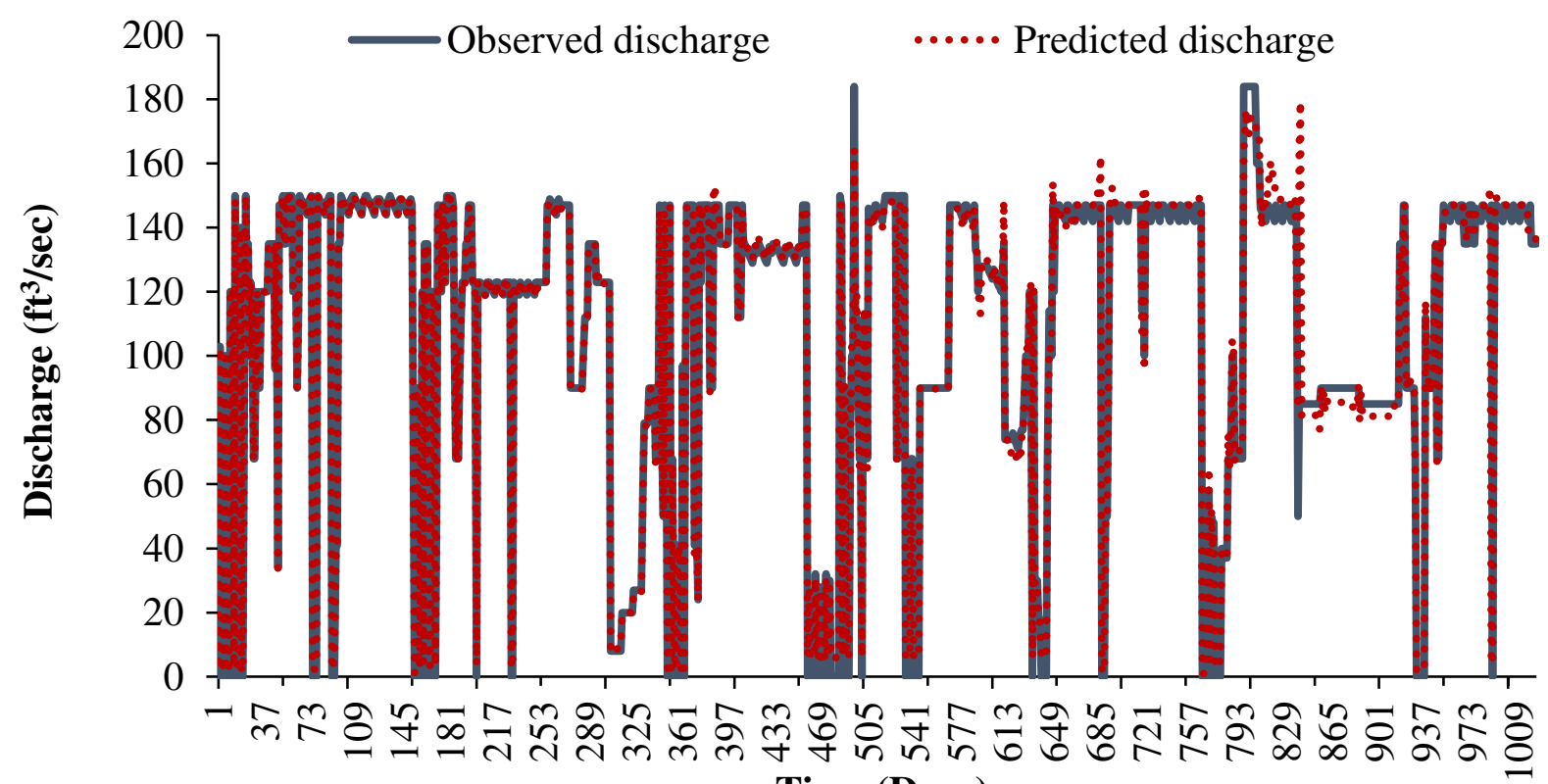

Time (Days)

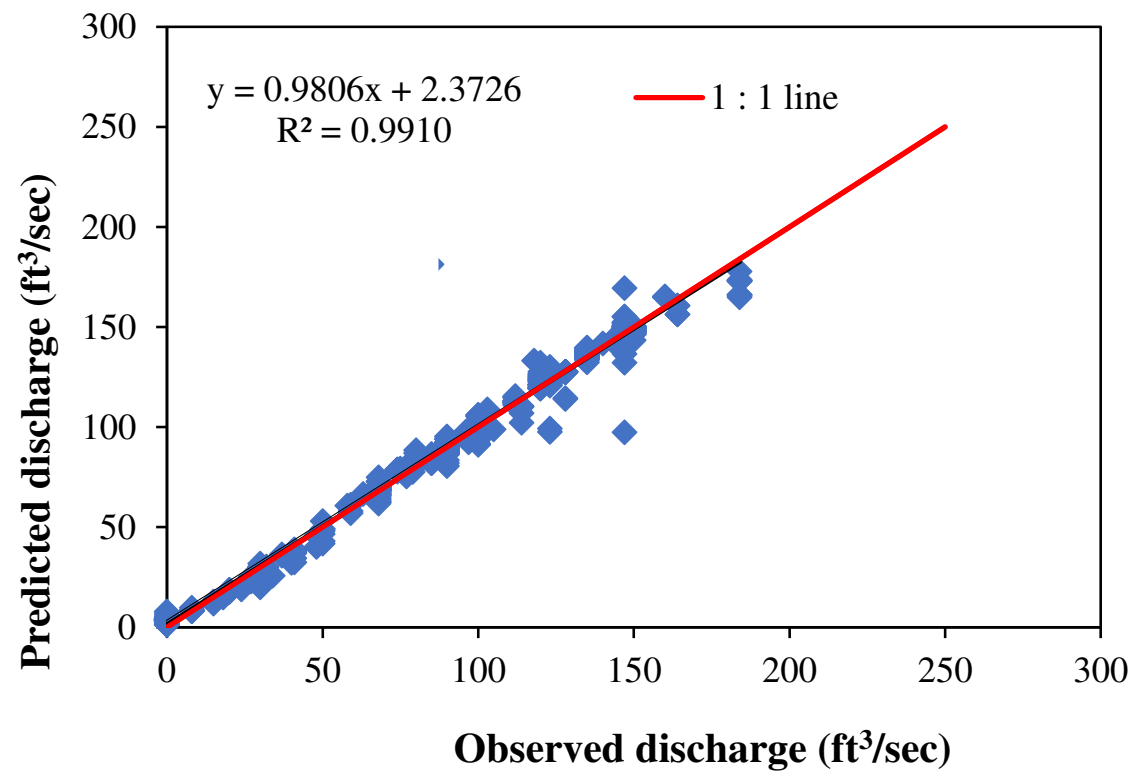

Fig. 8 Predicted and observed discharge and their corresponding scatter plot for WANN (12-25-

1) model during training period (01/06/2007 to $18 / 07 / 2015)$. 


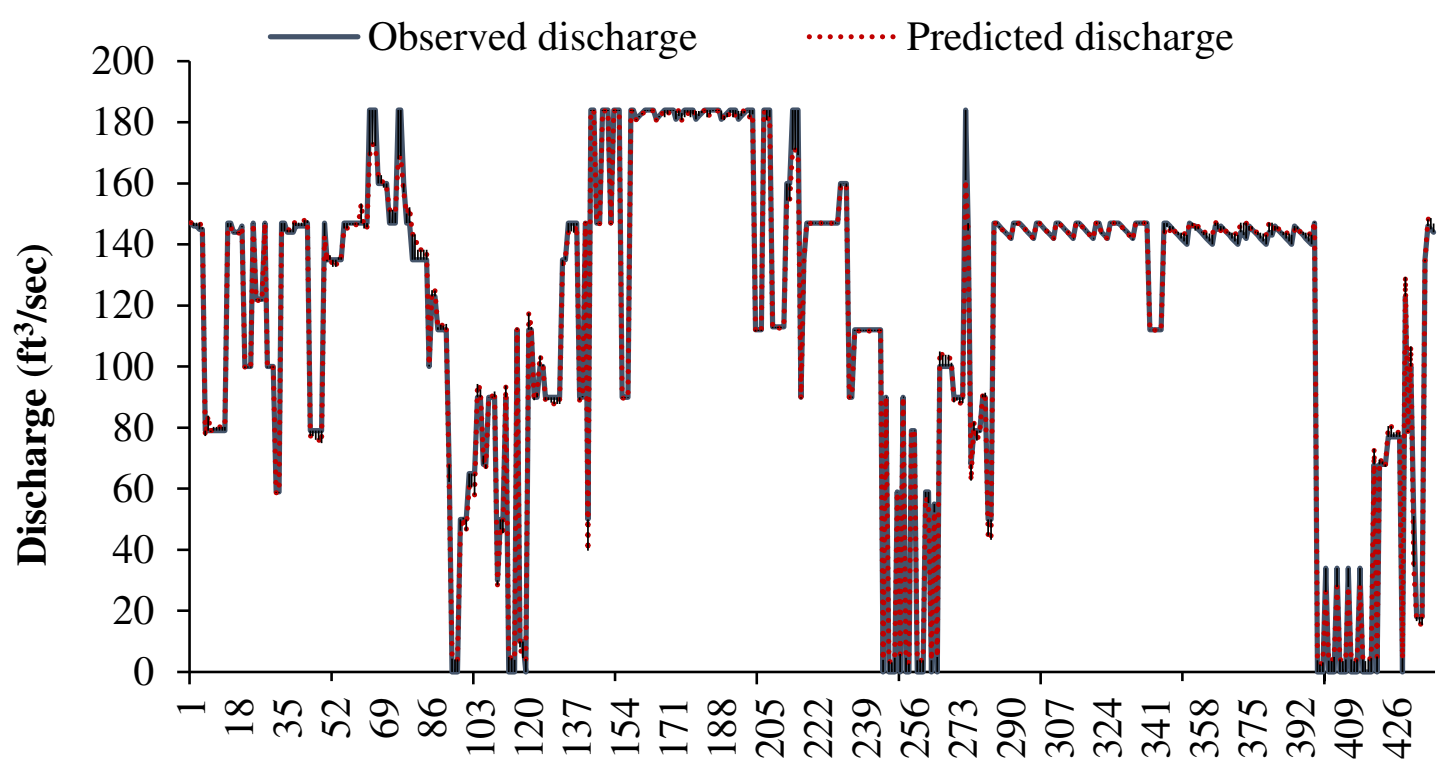

Time (Days)

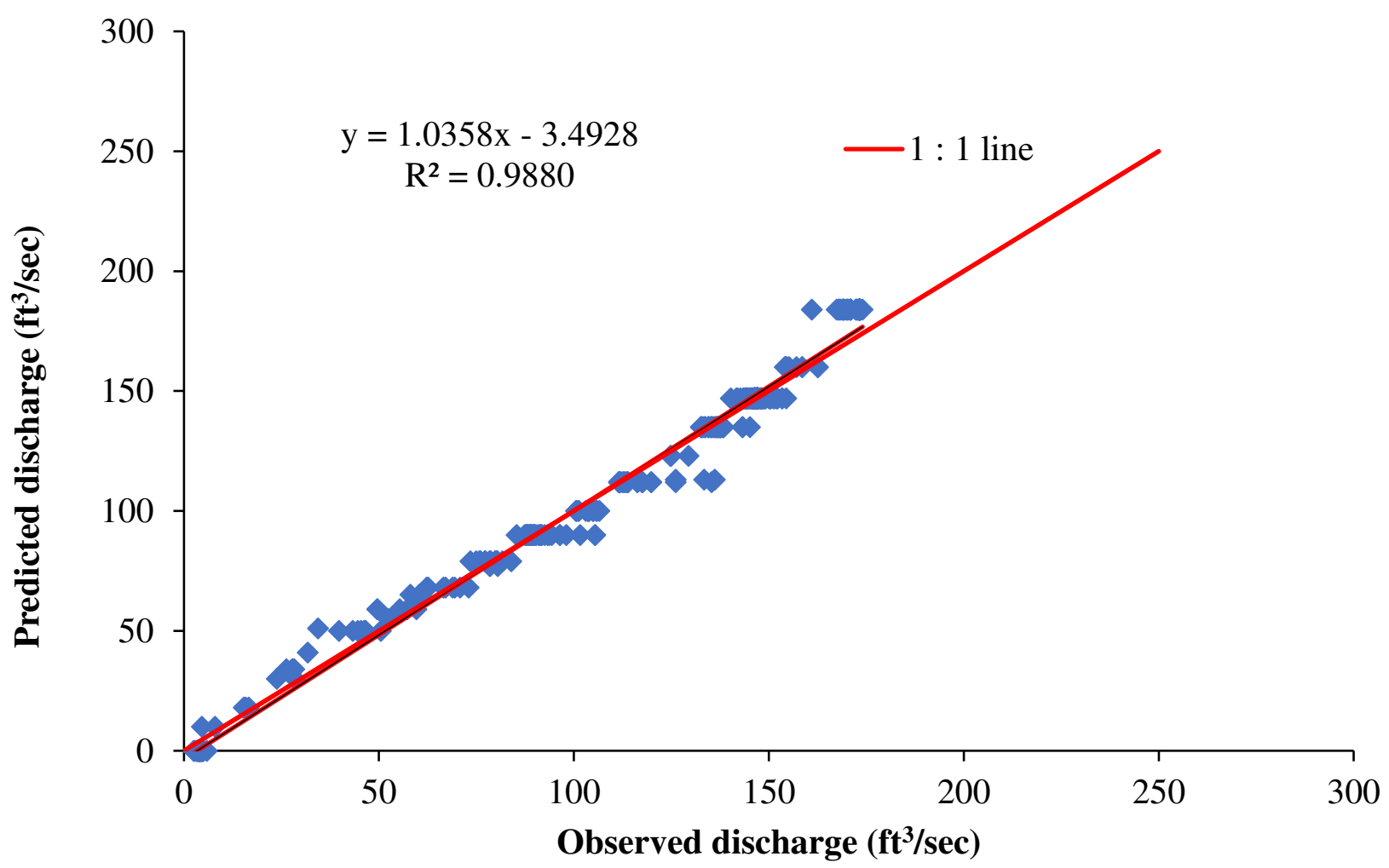

Fig. 9 Predicted and observed discharge and their corresponding scatter plot for WANN (12-251) model during testing period (19/07/2015 to 30/09/2018).

The Wavelet-based artificial neural network (WANN) modelsfor daily discharge predictionwere developed using the best input combinations considering lags of stage and discharge given by the Gamma test. In this Wavelet coupled ANN model, the first actual data of stage and discharge got 
transformed with three decomposition levels, reconstruction, and then put into developing the models. The network with a single hidden layer having higher values of PCC, WI, and COE and lower value lower values of RMSE was selected as the best model. The quantitative performance of different WANN models was assessed through different statistical and hydrological performance indicators, as presented in Table 8. It is revealed that RMSE, PCC, WI, and COE varied from 11.85 to $4.65 \mathrm{ft}^{3} / \mathrm{sec}, 0.87$ to $0.99,0.91$ to 0.98 , and 0.72 to 0.99 during training and testing, respectively. RMSE, PCC, WI, and COE values of the selected WANN-25 model were found to be $4.65 \mathrm{ft}^{3} / \mathrm{sec}, 0.99,0.98$, and 0.99 , respectively during training and $5.51 \mathrm{ft}^{3} / \mathrm{sec}, 0.99$, 0.96 and 0.99 , respectively during testing. 
Table 8 Comparison of various WANN models to select the best model during training and testing periods.

\begin{tabular}{|c|c|c|c|c|c|c|c|c|c|}
\hline \multirow{2}{*}{ Model } & \multirow{2}{*}{ Architecture } & \multicolumn{4}{|l|}{ Training } & \multicolumn{4}{|l|}{ Testing } \\
\hline & & RMSE(ft ( $^{3} /$ sec $\left.^{2}\right)$ & PCC & $\overline{W I}$ & $\mathrm{COE}$ & RMSE(ft (sec $\left.^{3}\right)$ & PCC & WI & $\mathrm{COE}$ \\
\hline WANN-1 & $12-1-1$ & 11.8560 & 0.9699 & 0.9649 & 0.9406 & 9.1805 & 0.9850 & 0.9170 & 0.9639 \\
\hline WANN-2 & $12-2-1$ & 9.0007 & 0.9828 & 0.9702 & 0.9658 & 8.5688 & 0.9856 & 0.9258 & 0.9685 \\
\hline WANN-3 & $12-3-1$ & 9.9451 & 0.9792 & 0.9653 & 0.9582 & 7.5953 & 0.9882 & 0.9370 & 0.9753 \\
\hline WANN-4 & $12-4-1$ & 6.3685 & 0.9914 & 0.9825 & 0.9829 & 6.8362 & 0.9920 & 0.9463 & 0.9800 \\
\hline WANN-5 & $12-5-1$ & 5.5280 & 0.9937 & 0.9787 & 0.9871 & 10.9847 & 0.9805 & 0.9837 & 0.9861 \\
\hline WANN-6 & $12-6-1$ & 5.7982 & 0.9929 & 0.9847 & 0.9858 & 10.9033 & 0.9744 & 0.9459 & 0.9491 \\
\hline WANN-7 & $12-7-1$ & 5.7100 & 0.9933 & 0.9794 & 0.9862 & 7.2179 & 0.9916 & 0.9383 & 0.9777 \\
\hline WANN-8 & $12-8-1$ & 6.5118 & 0.9912 & 0.9805 & 0.9821 & 6.4168 & 0.9924 & 0.9445 & 0.9824 \\
\hline WANN-9 & $12-9-1$ & 5.3610 & 0.9941 & 0.9826 & 0.9879 & 6.5155 & 0.9928 & 0.9453 & 0.9818 \\
\hline WANN-10 & $12-10-1$ & 5.3590 & 0.9939 & 0.9837 & 0.9879 & 7.0365 & 0.9898 & 0.9480 & 0.9788 \\
\hline WANN-11 & $12-11-1$ & 4.8389 & 0.9951 & 0.9859 & 0.9901 & 5.7197 & 0.9937 & 0.9537 & 0.9860 \\
\hline WANN-12 & $12-12-1$ & 8.1627 & 0.9859 & 0.9759 & 0.9718 & 7.8843 & 0.9875 & 0.9325 & 0.9734 \\
\hline WANN-13 & $12-13-1$ & 6.0035 & 0.9924 & 0.9861 & 0.9848 & 6.5410 & 0.9910 & 0.9533 & 0.9817 \\
\hline
\end{tabular}




\begin{tabular}{|c|c|c|c|c|c|c|c|c|c|}
\hline WANN-14 & $12-14-1$ & 5.8640 & 0.9931 & 0.9819 & 0.9855 & 6.2329 & 0.9925 & 0.9457 & 0.9834 \\
\hline WANN-15 & $12-15-1$ & 5.4803 & 0.9937 & 0.9837 & 0.9873 & 5.9711 & 0.9936 & 0.9503 & 0.9847 \\
\hline WANN-16 & $12-16-1$ & 8.0212 & 0.9871 & 0.9723 & 0.9728 & 7.2843 & 0.9918 & 0.9296 & 0.9773 \\
\hline WANN-17 & $12-17-1$ & 6.5554 & 0.9919 & 0.9763 & 0.9818 & 6.7425 & 0.9920 & 0.9365 & 0.9805 \\
\hline WANN-18 & $12-18-1$ & 5.0396 & 0.9947 & 0.9878 & 0.9893 & 5.4004 & 0.9935 & 0.9563 & 0.9875 \\
\hline WANN-19 & 12-19-1 & 5.6334 & 0.9933 & 0.9834 & 0.9866 & 6.1212 & 0.9927 & 0.9486 & 0.9839 \\
\hline WANN-20 & $12-20-1$ & 4.9586 & 0.9949 & 0.9824 & 0.9896 & 6.0462 & 0.9929 & 0.9503 & 0.9843 \\
\hline WANN-21 & $12-21-1$ & 4.7566 & 0.9955 & 0.9786 & 0.9904 & 6.9186 & 0.9902 & 0.9363 & 0.9795 \\
\hline WANN-22 & $12-22-1$ & 7.6611 & 0.9876 & 0.9787 & 0.9752 & 6.7957 & 0.9924 & 0.9440 & 0.9802 \\
\hline WANN-23 & $12-23-1$ & 5.9175 & 0.9927 & 0.9841 & 0.9852 & 5.7255 & 0.9938 & 0.9522 & 0.9860 \\
\hline WANN-25 & $12-25-1$ & 4.6522 & 0.9955 & 0.9882 & 0.9909 & 5.5121 & 0.9940 & 0.9684 & 0.9970 \\
\hline
\end{tabular}




\subsection{Comparison among ANN, ANFIS, and WANN models for discharge prediction}

The finest selected models were evaluated and compared with one another to determine the most precise estimation with the highest prediction performance when assessing the prediction accuracy for discharge prediction at the Gaula barrage location. A further round of comparisons was conducted between the best models identified from each approach, this time based on qualitative and quantitative performance evaluation criteria. Different performance measures, such as the Pearson correlation coefficient (PCC), root mean squared error (RMSE), the NashSutcliffe efficiency (CE), and Willmott Index (WI) and coefficient of determination $\left(\mathrm{R}^{2}\right)$, were utilized to determine the best accurate single model for daily discharge forecast at the Gaula barrage location. During testing periods, the performance of the best models picked from each technique is demonstrated using various performance indicators, as indicated in Table 9. It is evident from Table 9 that during testing, different indicators showed significant differences among different models. During testing RMSE, PCC, WI and COE varied from 2.20 to 5.51 $\mathrm{ft}^{3} / \mathrm{sec}, 0.99$ to $0.99,0.96$ to 0.98 and 0.99 to 0.99 , respectively.

As presented in Table 9, the ANFIS model outperformed the simple ANN model and WANN models. Among ANFIS models, Gaussian based ANFIS model with input MF-3 performed better. The best model should be selected by considering its performance during the testing period. As evident from Table 9, the ANFIS model performed better than all other models during testing periods. RMSE, PCC, WI, and COE values of the best selected ANFIS model were observed to be $2.2230,0.9990$ and 0.9897 , and 0.9979 during testing, respectively. The order of superiority for discharge prediction was observed as ANFIS, WANN, and ANN. After considering all models of different techniques, it was observed that the performance of Gaussian3 based ANFIS significantly achieves superior to all other models and could be applied for daily discharge prediction of Gaula barrage site. 
Table 9 Performance evaluation of best-chosen models during testing period using ANN, ANFIS and WANN approaches.

\begin{tabular}{llll}
\hline \multirow{2}{*}{$\begin{array}{l}\text { Performance } \\
\text { indicators }\end{array}$} & ANN network & ANFIS network & WANN network \\
\cline { 2 - 4 } & $\mathbf{3 - 6 - 1}$ & Gaussian-3 & $\mathbf{1 2 - 2 5 - 1}$ \\
\cline { 2 - 4 } & Testing period & Testing period & Testing period \\
\hline RMSE (ft $\left.{ }^{\mathbf{3}} / \mathbf{s e c}\right)$ & 4.25 & 2.22 & 5.51 \\
$\mathbf{r}$ & 0.99 & 0.99 & 0.99 \\
WI & 0.96 & 0.98 & 0.96 \\
CE & 0.99 & 0.99 & 0.99 \\
\hline
\end{tabular}

\section{Conclusion}

Discharge prediction is critically essential for water resource planning and management. The transformation of stage into discharge must be calculated through various non-linear equations. The present study was conducted to create and assess ANN, ANFIS, and WANN models for daily monsoon discharge forecasting at the Gaula site in the Indian state of Uttarakhand. The nonlinear correlations between input and output data sets can be identified using an ANN, a flexible, convenient, and simple mathematical framework. ANN is distributed, adaptive, and non-linear learning machine that is built from many neurons followed the training algorithm's instructions; each of these neurons gets links from other neurons or from itself. The artificial neural network (ANN) has a constructive approach that can analyze the complex non-linear relationship between dependent and independent data. The ANFIS model has become a trendy research tool due to its ability to exploit understanding of fuzzy logic while also leveraging the learning capabilities of an ANN at the same time, which is a rare combination. The ANFIS models were trained for discharge prediction using a hybrid learning method explicitly developed for this purpose. The appropriate learning parameter for the Gaula river location was achieved by trial and error using a 
Gaussian membership function and a TSK fuzzy rule, respectively. Based on the performance indices, among artificial neural network models, the ANN-6 model (3-6-1) outperformed other ANN models in daily discharge prediction. Wavelet coupled artificial neural network WANN-25 model outperformed other WANN models in daily discharge prediction for the study area. Adaptive neuro-fuzzy inference system ANFIS-08 (Gaussian) model outperformed other ANFIS models in daily discharge prediction for the study area. The ANFIS models performed better than ANN and WANN models in discharge prediction for the study area based on the overall performance.

\section{Acknowledgement}

Authors are grateful to the Department of Soil and Water Conservation Engineering, G. B. Pant University of Agriculture and Technology, Pantnagar, Uttarakhand, India. and to Gaula Barrage gauge station Haldwani-Kathgodam, Uttarakhand, India for providing data for this research.

\section{AUTHORS’ DECLARATIONS}

Conceived and designed the analysis: Ravi Shukla

Collected the data: Ravi Shukla,

Contributed data or analysis tools: Pravendra Kumar, Rohitashw Kumar

Performed the analysis: Pravendra Kumar

Writing review and editing: Rohitashw Kumar, Rawshan Ali, Alban Kuriqi and Dinesh Kumar Vishwakarma

Supervision: Pravendra Kumar

Corresponding author: Rohitashw Kumar

Conflicts of interest/Competing interests: The authors don't have any conflict of interests or any competing interests for the research. 
Funding Statement: There are no funding sources for the research.

Code availability: Not Applicable

Ethics approval: Not Applicable

Consent to participate: The authors express their consent to participate for research and review.

Consent for publication: The authors express their consent for publication of research work.

Data availability: The data cannot be made available because the policy of data providing agency.

\section{References}

1. Abebe AJ, Solomatine DP, Venneker RGW (2000) Application of adaptive fuzzy rulebased models for reconstruction of missing precipitation events. Hydrol Sci J 45:425436. https://doi.org/10.1080/02626660009492339.

2. Adnan RM, Petroselli A, Heddam S, et al (2021a) Comparison of different methodologies for rainfall-runoff modeling: machine learning vs conceptual approach. Nat Hazards 105:2987-3011. https://doi.org/10.1007/s11069-020-04438-2.

3. Adnan RM, Petroselli A, Heddam S, et al (2021b) Short term rainfall-runoff modelling using several machine learning methods and a conceptual event-based model. Stoch Environ Res Risk Assess 35:597-616. https://doi.org/10.1007/s00477-020-01910-0.

4. Akrami SA, Nourani V, Hakim SJS (2014) Development of Nonlinear Model Based on Wavelet-ANFIS for Rainfall Forecasting at Klang Gates Dam. Water Resour Manag 28:2999-3018. https://doi.org/10.1007/s11269-014-0651-x.

5. Al-Abadi AM (2016) Modeling of stage-discharge relationship for Gharraf River, southern Iraq using backpropagation artificial neural networks, M5 decision trees, and Takagi-Sugeno inference system technique: a comparative study. Appl Water Sci 6:407420. https://doi.org/10.1007/s13201-014-0258-7.

6. Alizadeh MJ, Kavianpour MR, Kisi O, Nourani V (2017) A new approach for simulating 
and forecasting the rainfall-runoff process within the next two months. J Hydrol 548:588597. https://doi.org/https://doi.org/10.1016/j.jhydrol.2017.03.032.

7. Amanabadi S, Vazirinia M, Vereecken H, et al (2019) Comparative Study of Statistical, Numerical and Machine Learning-based Pedotransfer Functions of Water Retention Curve with Particle Size Distribution Data. Eurasian Soil Sci 52:1555-1571. https://doi.org/10.1134/S106422931930001X.

8. Annayat W, Gupta A, Prakash KR, Sil BS (2021) Application of Artificial Neural Networks and Multiple Linear Regression for Rainfall-Runoff Modeling BT Communication Software and Networks. In: Satapathy SC, Bhateja V, Ramakrishna Murty M, et al. (eds). Springer Singapore, Singapore, pp 719-727.

9. Araghi A, Mousavi-Baygi M, Adamowski J, et al (2017) Forecasting soil temperature based on surface air temperature using a wavelet artificial neural network. Meteorol Appl 24:603-611. https://doi.org/https://doi.org/10.1002/met.1661

10. Atiaa AM (2015) Modeling of stage-discharge relationship for Gharraf River, southern Iraq by using data driven techniques: a case study. Water Util J 9:31-46.

11. Bajirao TS, Kumar P, Kumar M, et al (2021) Superiority of hybrid soft computing models in daily suspended sediment estimation in highly dynamic rivers. Sustain 13:129. https://doi.org/10.3390/su13020542.

12. Bayat H, Neyshaburi MR, Mohammadi K, et al (2013) Combination of artificial neural networks and fractal theory to predict soil water retention curve. Comput Electron Agric 92:92-103. https://doi.org/https://doi.org/10.1016/j.compag.2013.01.005

13. Bhattacharya B, Solomatine DP (2000) Application of artificial neural network in stagedischarge relationship. In: Proc. 4th International Conference on Hydroinformatics, Iowa City, USA. pp 1-7.

14. Coulibaly P, Burn DH (2004) Wavelet analysis of variability in annual Canadian $\begin{array}{lllll}\text { streamflows. } & \text { Water } & \text { Resour } & \text { Res }\end{array}$ 
https://doi.org/https://doi.org/10.1029/2003WR002667

15. D’Emilio A, Aiello R, Consoli S, et al (2018) Artificial Neural Networks for Predicting the Water Retention Curve of Sicilian Agricultural Soils. Water 10

16. Dalkiliç HY, Hashimi SA (2020) Prediction of daily streamflow using artificial neural networks (ANNs), wavelet neural networks (WNNs), and adaptive neuro-fuzzy inference system (ANFIS) models. Water 20:1396-1408. https://doi.org/10.2166/ws.2020.062

17. Dastorani MT, Moghadamnia A, Piri J, Rico-Ramirez M (2010) Application of ANN and ANFIS models for reconstructing missing flow data. Environ Monit Assess 166:421-434. https://doi.org/10.1007/s10661-009-1012-8.

18. Davies TR, Hall RJ (1992) A realistic strategy for disaster prevention. In: Internationales symposion: Interpraevent. pp 381-390.

19. Ebtehaj I, Bonakdari H (2014) Performance Evaluation of Adaptive Neural Fuzzy Inference System for Sediment Transport in Sewers. Water Resour Manag 28:47654779. https://doi.org/10.1007/s11269-014-0774-0.

20. Eryiğit M (2021) Estimation of parameters in groundwater modelling by modified Clonalg. J Hydroinformatics 23:298-306. https://doi.org/10.2166/hydro.2021.139

21. Fausett L V (2006) Fundamentals of neural networks: architectures, algorithms and applications. Pearson Education India.

22. Gabor D (1946) Theory of communication. Part 1: The analysis of information. J Inst Electr Eng - Part III Radio Commun Eng 93:429-441(12)

23. Genç O, Kişi Ö, Ardıçlıoğlu M (2014) Determination of Mean Velocity and Discharge in Natural Streams Using Neuro-Fuzzy and Neural Network Approaches. Water Resour Manag 28:2387-2400. https://doi.org/10.1007/s11269-014-0574-6

24. Govindaraju RS, Rao AR (2013) Artificial neural networks in hydrology. Springer Science \& Business Media. 
25. Güneş MŞ, Parim C, Yı1dız D, Büyüklü AH (2021) Predicting Monthly Streamflow Using a Hybrid Wavelet Neural Network: Case Study of the Çoruh River Basin. Polish J Environ Stud 30:3065-3075. https://doi.org/10.15244/pjoes/130767.

26. Hariharan G, Kannan K, Sharma KR (2009) Haar wavelet in estimating depth profile of soil temperature. Appl Math Comput 210:119-125. https://doi.org/https://doi.org/10.1016/j.amc.2008.12.036.

27. Haykin S (2010) Neural networks: a comprehensive foundation. 1999. Mc Millan, New Jersey 1-24.

28. Haykin S, Lippmann R (1994) Neural networks, a comprehensive foundation. Int J Neural Syst 5:363-364.

29. Herschy RW (1999) Hydrometry: Principles and Practice, 2nd Edn. ed.

30. Hornik K, Stinchcombe M, White H (1989) Multilayer feedforward networks are universal $\quad$ approximators. $\quad$ Neural Networks $\quad$ 2:359-366. https://doi.org/https://doi.org/10.1016/0893-6080(89)90020-8.

31. J. P, S. A, A. M, et al (2009) Daily Pan Evaporation Modeling in a Hot and Dry Climate. J Hydrol Eng 14:803-811. https://doi.org/10.1061/(ASCE)HE.1943-5584.0000056.

32. Jain SK (2012) Modeling river stage-discharge-sediment rating relation using support vector regression. Hydrol Res 43:851-861. https://doi.org/10.2166/nh.2011.101.

33. Jang J-. R (1993) ANFIS: adaptive-network-based fuzzy inference system. IEEE Trans Syst Man Cybern 23:665-685. https://doi.org/10.1109/21.256541.

34. KakaeiLafdani E, Moghaddam Nia A, Ahmadi A (2013) Daily suspended sediment load prediction using artificial neural networks and support vector machines. J Hydrol 478:50 62. https://doi.org/https://doi.org/10.1016/j.jhydrol.2012.11.048.

35. Kalteh AM (2015) Wavelet Genetic Algorithm-Support Vector Regression (Wavelet GASVR) for Monthly Flow Forecasting. Water Resour Manag 29:1283-1293. https://doi.org/10.1007/s11269-014-0873-y. 
36. Kambalimath S S, Deka PC (2021) Performance enhancement of SVM model using discrete wavelet transform for daily streamflow forecasting. Environ Earth Sci 80:101. https://doi.org/10.1007/s12665-021-09394-z.

37. Karahan H, Ayvaz MT (2008) Simultaneous parameter identification of a heterogeneous aquifer system using artificial neural networks. Hydrogeol J 16:817-827. https://doi.org/10.1007/s10040-008-0279-0.

38. Karimi B, Mohammadi P, Sanikhani H, et al (2020) Modeling wetted areas of moisture bulb for drip irrigation systems: An enhanced empirical model and artificial neural network. Comput Electron Agric 178:. https://doi.org/10.1016/j.compag.2020.105767.

39. Kennedy EJ (1984) Discharge ratings at gaging stations. Department of the Interior, US Geological Survey.

40. Khan MMH, Muhammad NS, El-Shafie A (2020) Wavelet based hybrid ANN-ARIMA models for meteorological drought forecasting. J Hydrol 590:125380. https://doi.org/https://doi.org/10.1016/j.jhydrol.2020.125380.

41. Li B, Cheng C (2014) Monthly discharge forecasting using wavelet neural networks with extreme learning machine. Sci China Technol Sci 57:2441-2452. https://doi.org/10.1007/s11431-014-5712-0.

42. Lippmann R (1987) An introduction to computing with neural nets. IEEE ASSP Mag 4:4-22. https://doi.org/10.1109/MASSP.1987.1165576.

43. Liu Y, Brown J, Demargne J, Seo D-J (2011) A wavelet-based approach to assessing timing errors in hydrologic predictions. J Hydrol 397:210-224. https://doi.org/https://doi.org/10.1016/j.jhydrol.2010.11.040.

44. Malik A, Kumar A, Kisi O (2018) Daily pan evaporation estimation using heuristic methods with gamma test. J Irrig Drain Eng 144:. https://doi.org/10.1061/(ASCE)IR.1943-4774.0001336.

45. Malik A, Kumar A, Piri J (2017) Daily suspended sediment concentration simulation 
using hydrological data of Pranhita River Basin, India. Comput Electron Agric 138:20 28. https://doi.org/https://doi.org/10.1016/j.compag.2017.04.005.

46. Nayak PC, Sudheer KP, Rangan DM, Ramasastri KS (2004) A neuro-fuzzy computing technique for modeling hydrological time series. J Hydrol 291:52-66. https://doi.org/https://doi.org/10.1016/j.jhydrol.2003.12.010.

47. Nourani V, Andalib G (2015) Wavelet Based Artificial Intelligence Approaches for Prediction of Hydrological Time Series BT - Artificial Life and Computational Intelligence. In: Chalup SK, Blair AD, Randall M (eds). Springer International Publishing, Cham, pp 422-435.

48. Nourani V, Komasi M (2013) A geomorphology-based ANFIS model for multi-station modeling of rainfall-runoff process. J Hydrol 490:41-55. https://doi.org/https://doi.org/10.1016/j.jhydrol.2013.03.024.

49. Özger M (2010) Significant wave height forecasting using wavelet fuzzy logic approach. Ocean Eng $37: 1443-1451$. https://doi.org/https://doi.org/10.1016/j.oceaneng.2010.07.009.

50. Özgür K (2009) Neural Networks and Wavelet Conjunction Model for Intermittent $\begin{array}{lllll}\text { Streamflow } & \text { Forecasting. } & \mathrm{J} & \text { Hydrol } & \text { Eng }\end{array}$ https://doi.org/10.1061/(ASCE)HE.1943-5584.0000053.

51. Partal T, Küçük M (2006) Long-term trend analysis using discrete wavelet components of annual precipitations measurements in Marmara region (Turkey). Phys Chem Earth, Parts A/B/C 31:1189-1200. https://doi.org/https://doi.org/10.1016/j.pce.2006.04.043

52. Rajaee T, Mirbagheri SA, Zounemat-Kermani M, Nourani V (2009) Daily suspended sediment concentration simulation using ANN and neuro-fuzzy models. Sci Total Environ 407:4916-4927. https://doi.org/https://doi.org/10.1016/j.scitotenv.2009.05.016.

53. Rath S, Nayak PC, Chatterjee C (2013) Hierarchical neurofuzzy model for real-time flood forecasting. Int $\mathrm{J}$ River Basin Manag 11:253-268. 
https://doi.org/10.1080/15715124.2013.798329.

54. Rehamnia I, Benlaoukli B, Jamei M, et al (2021) Simulation of seepage flow through embankment dam by using a novel extended Kalman filter based neural network paradigm: Case study of Fontaine Gazelles Dam, Algeria. Measurement 176:109219. https://doi.org/https://doi.org/10.1016/j.measurement.2021.109219.

55. Remesan R, Shamim MA, Han D, Mathew J (2009) Runoff prediction using an integrated hybrid modelling $\quad$ scheme. J Hydrol 372:48-60. https://doi.org/https://doi.org/10.1016/j.jhydrol.2009.03.034.

56. Sadeghi-Tabas S, Samadi SZ, Akbarpour A, Pourreza-Bilondi M (2016) Sustainable groundwater modeling using single- and multi-objective optimization algorithms. J Hydroinformatics 19:97-114. https://doi.org/10.2166/hydro.2016.006.

57. Saha M, Mitra P, Chakraborty A (2015) Fuzzy Clustering-Based Ensemble Approach to Predicting Indian Monsoon. Adv Meteorol 2015:329835. https://doi.org/10.1155/2015/329835.

58. Sahay RR, Srivastava A (2014) Predicting Monsoon Floods in Rivers Embedding Wavelet Transform, Genetic Algorithm and Neural Network. Water Resour Manag 28:301-317. https://doi.org/10.1007/s11269-013-0446-5.

59. Sanikhani H, Kisi O, Maroufpoor E, Yaseen ZM (2019) Temperature-based modeling of reference evapotranspiration using several artificial intelligence models: application of different modeling scenarios. Theor Appl Climatol 135:449-462. https://doi.org/10.1007/s00704-018-2390-z.

60. Saraiva SV, Carvalho F de O, Santos CAG, et al (2021) Daily streamflow forecasting in Sobradinho Reservoir using machine learning models coupled with wavelet transform and bootstrapping. Appl Soft Comput 102:107081. https://doi.org/https://doi.org/10.1016/j.asoc.2021.107081.

61. Sehgal V, Sahay RR, Chatterjee C (2014a) Effect of Utilization of Discrete Wavelet 
Components on Flood Forecasting Performance of Wavelet Based ANFIS Models. Water Resour Manag 28:1733-1749. https://doi.org/10.1007/s11269-014-0584-4.

62. Sehgal V, Tiwari MK, Chatterjee C (2014b) Wavelet bootstrap multiple linear regression based hybrid modeling for daily river discharge forecasting. Water Resour Manag 28:2793-2811.

63. Seo Y, Kim S, Kisi O, Singh VP (2015) Daily water level forecasting using wavelet decomposition and artificial intelligence techniques. J Hydrol 520:224-243. https://doi.org/https://doi.org/10.1016/j.jhydrol.2014.11.050.

64. Shiri J, Kisi O (2010) Short-term and long-term streamflow forecasting using a wavelet and neuro-fuzzy conjunction model. J Hydrol 394:486-493. https://doi.org/https://doi.org/10.1016/j.jhydrol.2010.10.008.

65. Shoaib M, Shamseldin AY, Melville BW, Khan MM (2016) A comparison between wavelet based static and dynamic neural network approaches for runoff prediction. J Hydrol 535:211-225. https://doi.org/https://doi.org/10.1016/j.jhydrol.2016.01.076.

66. Sihag P, Tiwari NK, Ranjan S (2019a) Prediction of unsaturated hydraulic conductivity using adaptive neuro- fuzzy inference system (ANFIS). ISH J Hydraul Eng 25:132-142. https://doi.org/10.1080/09715010.2017.1381861.

67. Sihag P, Tiwari NK, Ranjan S (2017) Modelling of infiltration of sandy soil using gaussian process regression. Model Earth Syst Environ 3:1091-1100. https://doi.org/10.1007/s40808-017-0357-1.

68. Sihag P, Tiwari NK, Ranjan S (2019b) Prediction of unsaturated hydraulic conductivity using adaptive neuro-fuzzy inference system (ANFIS). ISH J Hydraul Eng 25:132-142.

69. Singh A, Malik A, Kumar A, Kisi O (2018) Rainfall-runoff modeling in hilly watershed using heuristic approaches with gamma test. Arab J Geosci 11:261. https://doi.org/10.1007/s12517-018-3614-3.

70. Stefánsson A, Končar N, Jones AJ (1997) A note on the Gamma test. Neural Comput 
Appl 5:131-133. https://doi.org/10.1007/BF01413858.

71. Sudheer C, Maheswaran R, Panigrahi BK, Mathur S (2014) A hybrid SVM-PSO model for forecasting monthly streamflow. Neural Comput Appl 24:1381-1389. https://doi.org/10.1007/s00521-013-1341-y.

72. Taormina R, Chau K-W (2015) ANN-based interval forecasting of streamflow discharges using the LUBE method and MOFIPS. Eng Appl Artif Intell 45:429-440. https://doi.org/https://doi.org/10.1016/j.engappai.2015.07.019.

73. Tayfur G, Singh VP (2011) Predicting Mean and Bankfull Discharge from Channel Cross-Sectional Area by Expert and Regression Methods. Water Resour Manag 25:12531267. https://doi.org/10.1007/s11269-010-9741-6.

74. Vafakhah M, Kahneh E (2016) A comparative assessment of adaptive neuro-fuzzy inference system, artificial neural network and regression for modelling stage-discharge

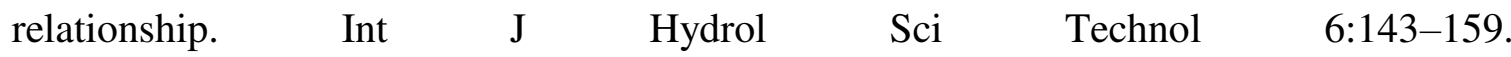
https://doi.org/10.1504/IJHST.2016.075581.

75. Vahid N, Ali DT, Amir M, Huseyin G (2019) Hybrid Wavelet-M5 Model Tree for Rainfall-Runoff Modeling. J $\quad$ J $\quad$ Hydrol $\quad$ Eng $\quad$ 24:4019012. https://doi.org/10.1061/(ASCE)HE.1943-5584.0001777.

76. Wang J, Bao W, Gao Q, et al (2021) Coupling the Xinanjiang model and wavelet-based random forests method for improved daily streamflow simulation. J Hydroinformatics 23:589-604. https://doi.org/10.2166/hydro.2021.111.

77. Wu W, Tang X-P, Guo N-J, et al (2013) Spatiotemporal modeling of monthly soil temperature using artificial neural networks. Theor Appl Climatol 113:481-494. https://doi.org/10.1007/s00704-012-0807-7. 